\title{
Sensitivity of tropical cyclone Jal simulations to physics parameterizations
}

\author{
R Chandrasekar and C BALAJ** \\ Department of Mechanical Engineering, Indian Institute of Technology, Madras, Chennai 600 036, India. \\ ${ }^{*}$ Corresponding author.e-mail: balaji@iitm.ac.in
}

In this study, the sensitivity of numerical simulations of tropical cyclones to physics parameterizations is carried out with a view to determine the best set of physics options for prediction of cyclones originating in the north Indian Ocean. For this purpose, the tropical cyclone Jal has been simulated by the advanced (or state of science) mesoscale Weather Research and Forecasting (WRF) model on a desktop mini super computer CRAY CX1 with the available physics parameterizations. The model domain consists of one coarse and two nested domains. The resolution of the coarse domain is $90 \mathrm{~km}$ while the two nested domains have resolutions of 30 and $10 \mathrm{~km}$, respectively. The results from the inner most domain have been considered for analyzing and comparing the results. Model simulation fields are compared with corresponding analysis or observation data. The track and intensity of simulated cyclone are compared with best track estimates provided by the Joint Typhoon Warning Centre (JTWC) data. Two sets of experiments are conducted to determine the best combination of physics schemes for track and intensity and it is seen that the best set of physics combination for track is not suitable for intensity prediction and the best combination for track prediction overpredicts the intensity of the cyclone. The sensitivity of the results to orography and level of nesting has also been studied. Simulations were also done for the cyclone Aila with (i) best set of physics and (ii) randomly selected physics schemes. The results of the Aila case show that the best set of physics schemes has more prediction skill than the randomly selected schemes in the case of track prediction. The cumulus (CPS), planetary boundary layer (PBL) and microphysics (MP) parameterization schemes have more impact on the track and intensity prediction skill than the other parameterizations employed in the mesoscale model.

\section{Introduction}

Tropical cyclones (TC) are important weather phenomena that cause heavy wind, torrential rain and enormous damage to life and property when they cross the coastal regions. Accurate predictions of TC track and intensity with timely warning to people will minimise loss of life and property. Availability of state-of-the-art numerical weather prediction (NWP) models along with efficient computing facilities to carry out simulations has made possible the prediction of the mesoscale weather events. The prediction of TCs using mesoscale NWP models is highly influenced by initial/boundary conditions and physics parameterizations employed in the model. In view of this, 'fixing' the one best combination of physics schemes in the mesoscale NWP models for the whole globe is formidable. Further, the NWP model performance is very sensitive to grid sizes and the geographical region of interest. The best set of schemes for one region may not be suitable for some other region. The horizontal and vertical resolutions are also very important

Keywords. Cyclones; track and intensity prediction; WRF; physics parameterizations. 
factors, since different parameterization schemes can give different results for different model resolutions. Sensitivity experiments are the only logical way to identifying the best set of physics schemes for a particular region. Srinivas et al. (2007) conducted a sensitivity study of the Andhra severe cyclone (2003) by using the National Center for Atmospheric Research (NCAR) fifth generation non-hydrostatic mesoscale model (MM5). They reported that the planetary boundary Layer (PBL) schemes and convective parameterization schemes (CPS) play an important role in predicting both the intensity and movement of the model simulated storms. They also concluded that the combination of Mellor Yamada (MY) scheme for PBL parameterization and Kain-Fritch 2 (KF2) scheme as the CPS give the best results in terms of intensity and track. A sensitivity study of the Orissa super cyclone by Rao and Prasad (2007) also indicates that a combination of the MY scheme from the PBL and KF2 from CPS gives better results in terms of cyclone track and intensity prediction. Deshpande et al. (2010) however conclude that the prediction of cyclone track and intensity are highly sensitive to only convective parameterization schemes compared to other physical parameterization schemes based on their studies on cyclone Gonu using the MM5 model. Loh et al. (2010) also report that the PBL parameterization schemes do not significantly affect track and intensity prediction of near equatorial typhoons. Prater and Evans (2002) modeled the tropical cyclone Irene (1999) with various CPS and concluded that the Kain-Fritsch (KF) scheme in MM5 produces relatively accurate storm predictions compared to observations. Mandal et al. (2004) simulated two severe tropical cyclones in the Bay of Bengal using MM5 with various CPS, PBL and radiation schemes and inferred that the combination of Medium Range Forecast (MRF) scheme in PBL and Grell scheme in CPS with Community Climate Model Version 2 (CCM2) scheme in radiation gives better performance in so far as track and intensity predictions are concerned. Yang and Ching (2005) also concluded that the MRF in PBL and Grell in CPS combined with the Goddard Graupel in cloud microphysics scheme give the best performance in the study of typhoon Toraji (2001). Based on a study of impact of cloud microphysics on hurricane Charley, Pattnaik and Krishnamurti (2007) reported that the microphysical parameterization schemes have strong impact on the intensity prediction of hurricane but have negligible impact on the track forecast. Krieger (2009) analyzed the sensitivity of Advanced Research WRF (ARW) v 3.0 model on the Beaufort Sea region with the available physics parameterization schemes and concluded that the combination of $\mathrm{KF}$ scheme for CPS, Pleim-Xu scheme for land surface and asymmetrical convective model 2 (ACM2) scheme for PBL produces better surface wind prediction agreement with both station observations and Quick Scatterometer(QuikSCAT) surface wind data. The above studies on regional weather models clearly indicate that the best combinations of physics parameterization schemes are very essential to predict a mesoscale weather system. Previous sensitivity studies on mesoscale models were mostly initiated with NCEP Final analysis (FNL) data as initial and boundary conditions. Very few studies have been initiated with the NCEP Global Forecast System (GFS) real time prediction. In this study, the sensitivity of a very recent tropical cyclone Jal to model physics parameterization is conducted with GFS real time predictions as the initial and boundary conditions. Use of GFS real time prediction is akin to running a real time forecast. Furthermore, most of the previous sensitivity studies have been done with only combinations of Cumulus, PBL and microphysics parameterizations and very few studies consider different radiation schemes and other physics options. In this study, all physics parameterizations available in the ARW v 3.1.1 model are systematically evaluated.

\section{Synoptic history of Jal}

Cyclone Jal was the fourth severe cyclonic storm of the north Indian Ocean in 2010. Jal developed from a low pressure area in the South China Sea and organized into a tropical depression on October 28. Late on November 1, the tropical depression crossed the Malay peninsula, and entered the extreme eastern part of the Indian Ocean, and moved continuously towards the west and entered the Bay of Bengal on 4 November 2010. The system further strengthened on November 4 18 UTC (Coordinated Universal Time) and the JTWC declared it as a tropical storm with a maximum wind speed of $19.16 \mathrm{~m} / \mathrm{s}$. Later the storm moved west, gained energy from the warm waters and strengthened again as a category 1 storm on November 600 UTC and continued till November 706 UTC as a category 1 storm. The system weakened and became a deep depression after its landfall near Chennai at 18 UTC on November 7.

\section{Description of the model}

The model used in this study is the Advanced Research WRF (ARW) v 3.1.1 model, a widely used community mesoscale model developed by NCAR. The ARW is a next generation of NCAR 
Table 1. Model physics parameterization schemes.

\begin{tabular}{|c|c|}
\hline \multicolumn{2}{|l|}{ Cumulus } \\
\hline 1. Kain-Fritsch(new Eta) scheme & $\mathrm{KF}$ \\
\hline 2. Betts-Miller-Janjic scheme & BMJ \\
\hline 3. Grell-Devenyi ensemble scheme & GD \\
\hline 4. New Grell scheme & GRE \\
\hline \multicolumn{2}{|l|}{ PBL } \\
\hline 1. Yonsei University scheme & YSM \\
\hline 2. Mellor-Yamada-janjic(Eta) TKE scheme & MYJ \\
\hline $\begin{array}{l}\text { 3. Quasi-Normal Scale Elimination } \\
\text { (turbulence theory) }\end{array}$ & QNSE \\
\hline $\begin{array}{l}\text { 4. Mellor-Yamada-Nakanishi-Niino } \\
2.5 \text { level TKE }\end{array}$ & MYNN2.5 \\
\hline $\begin{array}{l}\text { 5. Mellor-Yamada-Nakanishi-Niino } \\
3 \text { levelTKE }\end{array}$ & MYNN3 \\
\hline $\begin{array}{l}\text { 6. Asymmetrical Convective Model } \\
\text { version } 2\end{array}$ & ACM2 \\
\hline 7. Bougeault and Lacarrere & BOULAC \\
\hline \multicolumn{2}{|l|}{ Microphysics } \\
\hline 1. Kessler scheme & $\mathrm{KS}$ \\
\hline 2. Lin et al. scheme & LIN \\
\hline $\begin{array}{l}\text { 3. WRF Single Moment 3-class simple } \\
\text { ice scheme }\end{array}$ & WSM3 \\
\hline 4. WRF Single Moment 5-class scheme & WSM5 \\
\hline 5. Ferrier (new Eta) microphysics & FERRIER \\
\hline $\begin{array}{l}\text { 6. WRF Single Moment 6-class } \\
\text { graupel scheme }\end{array}$ & WSM6 \\
\hline 7. Goddard GCE scheme & GODDARD \\
\hline 8. Thompson graupel scheme 2 moment & THOM2 \\
\hline 9. Morrison 2-moment scheme & MORRISON \\
\hline 10. Double moment, 5-class scheme & DM5 \\
\hline 11. Douple moment, 6-class scheme & DM6 \\
\hline 12. Thompson scheme & THOMP \\
\hline \multicolumn{2}{|l|}{ sfsfclayphysics } \\
\hline 1. Monin-Obukhov scheme & MON \\
\hline 2. Monin-Obukhov (Janjic Eta) scheme & JAN \\
\hline $\begin{array}{l}\text { 3. Quasi-Normal Scale elimination } \\
\text { (turbulence theory) }\end{array}$ & QNSE_SF \\
\hline 4. Mellor-Yamada-Nakanishi-Niino scheme & MYNN_SF \\
\hline 5. Pleim-Xu scheme & PLEIM_SF \\
\hline \multicolumn{2}{|l|}{ sfsurfacephysics } \\
\hline 1. Thermal diffusion scheme & $\mathrm{TD}$ \\
\hline 2. Unified Noah land surface model & NLS \\
\hline 3. Rapid update cycle land-surface model & RUC \\
\hline 4. Pleim-Xu scheme & PLEIM \\
\hline \multicolumn{2}{|l|}{ Long wave radiation (LWR) } \\
\hline 1. Rapid Radiative Transfer Model & RRTM \\
\hline $\begin{array}{l}\text { 2. Rapid Radiative Transfer Model } \\
\text { for Global }\end{array}$ & RRTMG \\
\hline \multicolumn{2}{|l|}{ Short wave radiation (SWR) } \\
\hline 1. Dudhia scheme & DS \\
\hline 2. Goddard short wave & GSW \\
\hline $\begin{array}{l}\text { 3. Rapid Radiative Transfer Model } \\
\text { for Global }\end{array}$ & RRTMG \\
\hline
\end{tabular}

fifth generation mesoscale model (MM5) which incorporates recent and new physics parameterization schemes including some of the schemes from the MM5 model. The available physics parameterization schemes in the ARW model are detailed in NCAR technical notes by Skamarock (2008). The ARW can be used for both research and operational applications. It is a non-hydrostatic mesoscale model with run-time hydrostatic option. The model dynamic solver integrates the flux form of compressible non-hydrostatic Euler equation. The variables in this equation are conservative properties following the philosophy of Ooyama (1990). The equations are formulated using a terrain following mass vertical co-ordinate following Laprise (1992). In the ARW solver, a time-split integration scheme is used for solving the compressible non-hydrostatic Euler equation. The third-order Runge-Kutta (RK3) has been used for the time-split integration scheme, while the high-frequency acoustic waves are integrated over smaller time steps to maintain numerical stability. The horizontal propagating acoustic waves are integrated by a forward-backward time integration scheme and the vertically propagating acoustic waves and buoyancy oscillations are integrated using the vertically implicit scheme with acoustic time steps. The integrating schemes and other technical descriptions of solver dynamics are detailed in Skamarock and Klemp (2008). The physics parameterization schemes used in the present study to investigate the sensitivity of the tropical cyclone Jal are listed in table 1.

\section{Description of model domains and dynamic options}

Numerical experiments are conducted with three domains (one coarse and two nested), as shown in figure 1. All the three domains are run simultaneously by two-way nested run options. The horizontal grid resolution of the coarse domain is $90 \mathrm{~km}$ and it covers the entire north Indian Ocean. As already mentioned, cyclone Jal entered the Bay of Bengal and hit the east coast on 7 November 18 UTC 2010, and so these regions are covered with a high resolution $(10 \mathrm{~km})$ domain. Such a high resolution also enables us to incorporate the orographic effects due to the presence of the Himalayas as well as the Western Ghats. The details of domains and dynamic options that have been used in the ARW model are listed in table 2.

\section{Model initial and boundary conditions and verification data}

The United States Geological Survey (USGS) 30" resolution terrain topographical data have been 


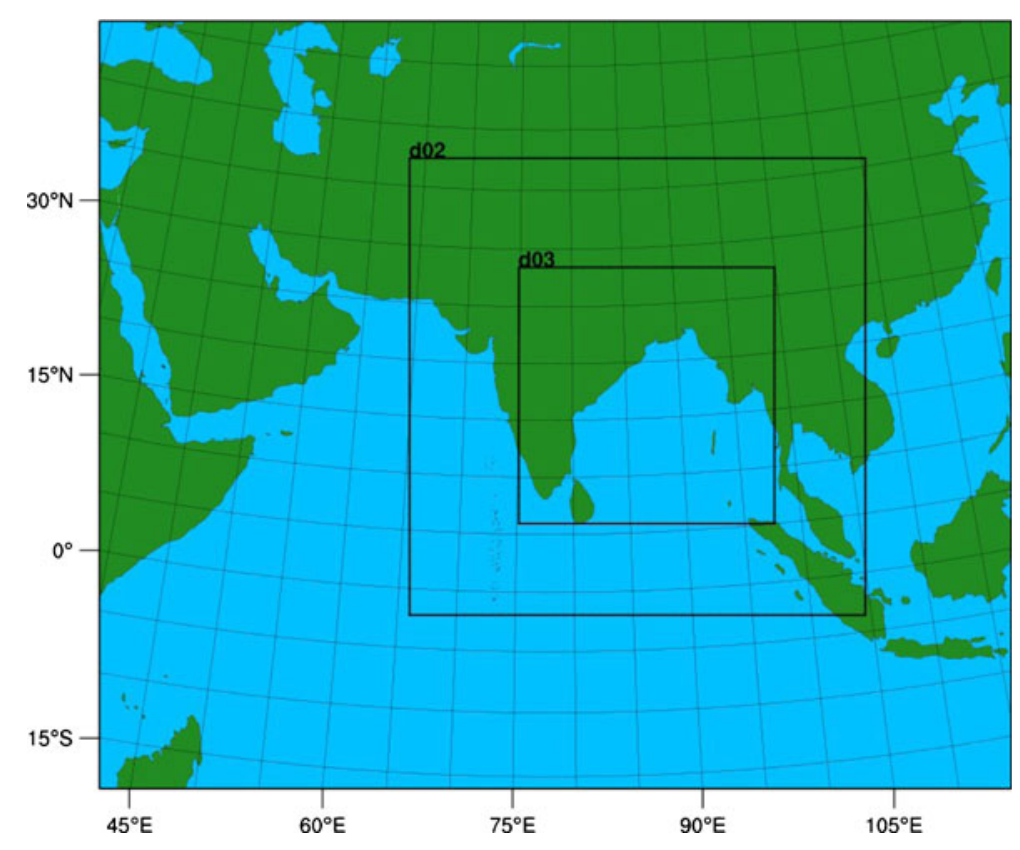

Figure 1. Model domain employed in the present study, 4 November 2010, 18 UTC. The resolution of the domain d01 is $90 \mathrm{~km}$, domain d02 is $30 \mathrm{~km}$ and domain d03 is $10 \mathrm{~km}$.

used for all three domains in the WRF preprocessing system (WPS). The $0.5^{\circ}$ resolution Global Forecast System (GFS) real time prediction from the National Center for Environmental Prediction (NCEP) has been used as initial and boundary conditions. Simulations were initiated on 4 November 201018 UTC with lateral boundary conditions and were carried out up to 8 November 201006 UTC. The lateral boundary conditions are available at 3 -hr intervals. Though the model has been run up to $84 \mathrm{hr}$, only $72 \mathrm{hr}$ simulations have been analyzed and compared with observations. The JTWC observed cyclone track data and retrieval cyclone intensity data are used to compare the model simulated track and intensity.

\section{Experimental procedure and scheme selection}

Sensitivity studies for the tropical cyclone Jal have carried out as two sets of experiments in order to determine the best combination of physics parameterization schemes for (i) track and (ii) intensity prediction. Results from the $10 \times 10 \mathrm{~km}$ nested domain have been used for analyzing the cyclone. The aim of the first set of experiments is to determine the best combination for track prediction and that of the second set is to do the same for intensity prediction. In both the experiments, prior knowledge available from previous model sensitivity studies reported in the literature have been

Table 2. Model dynamics and domain details.

\begin{tabular}{ll}
\hline Dynamics & \\
Equation & Non-hydrostatic \\
Time integration scheme & Third-order Runge-Kutta scheme \\
Horizontal grid type & Arakawa-C grid \\
Domain & \\
Map projection & Lambert conformal mapping \\
Central point of the domain & $78^{\circ} \mathrm{E}, 16^{\circ} \mathrm{N}$ \\
No. of domains & $3($ one coarse and two nested) \\
No. of vertical layers & 27 sigma levels \\
Horizontal grid distance & $90 \mathrm{~km}, 30 \mathrm{~km}, 10 \mathrm{~km}$ for domain $1,2,3$ respectively \\
Time step & $270 \mathrm{~s}, 90 \mathrm{~s}, 30 \mathrm{~s}$ for domain $1,2,3$ respectively \\
No. of grid points & $101(\mathrm{EW}), 85(\mathrm{SN})$ in domain 1 \\
& $151(\mathrm{EW}), 151(\mathrm{SN})$ in domain 2 \\
& $250(\mathrm{EW}), 250(\mathrm{SN})$ in domain 3 \\
\hline
\end{tabular}


incorporated, wherever appropriate. From several studies in the past, it is clear that cumulus parameterization (CPS) schemes have more impact on the track and intensity predictions. In view of these findings, CPS sensitivity has been studied first in both the sets of experiments. This is followed by the PBL and cloud microphysics (MP) parameterization sensitivity studies. The other parameterization schemes of land surface, short wave radiation (SWR) and long wave radiation (LWR) follow the PBL and MP sensitivity studies (see table 3). For the track experiments, the minimum central sea level pressure (CSLP) (hPa) and corresponding latitude and longitude values have been obtained for every 6 hours from the ARW model output for all schemes in a particular physics parameterization.
The model simulated tracks for the cyclone Jal have then been compared with the JTWC observation track and the track error is computed as given in equation (1). The root mean square (RMS) error has also been calculated up to $72 \mathrm{hr}$ for every 6 hours, as given in equation (2).

$$
\begin{gathered}
T_{\mathrm{Err}}=\sqrt{\left(\text { lat }_{\mathrm{jtwc}}-l a t_{\mathrm{wrf}}\right)^{2}+\left(\operatorname{lon}_{\mathrm{jtwc}}-\operatorname{lon}_{\mathrm{wrf}}\right)^{2}} \\
R M S=\sqrt{\frac{1}{n} \sum_{i=1}^{n} T_{\mathrm{Err}_{\mathrm{i}}}^{2}}
\end{gathered}
$$

where $T_{\text {Err }}$ is the track error in degrees, the subscripts jtwc and wrf refer to the latitude and

\begin{tabular}{|c|c|c|c|c|c|c|}
\hline $\begin{array}{l}\text { Exp. } \\
\text { no. }\end{array}$ & Cumulus & PBL & Microphysics & $\begin{array}{l}\text { Surface } \\
\text { physics }\end{array}$ & SWR & LWR \\
\hline \multicolumn{7}{|c|}{ Experiments with cumulus parameterization schemes } \\
\hline 1 & $\mathrm{KF}$ & YSU/MON & THOM2 & $\mathrm{TD}$ & DS & RRTM \\
\hline 2 & BMJ & YSU/MON & THOM2 & $\mathrm{TD}$ & DS & RRTM \\
\hline 3 & GD & YSU/MON & THOM2 & $\mathrm{TD}$ & DS & RRTM \\
\hline 4 & GRELL & YSU/MON & THOM2 & $\mathrm{TD}$ & DS & RRTM \\
\hline \multicolumn{7}{|c|}{ Experiments with PBL schemes } \\
\hline 5 & $\mathrm{KF}$ & MYJ/JAN & THOM2 & $\mathrm{TD}$ & DS & RRTM \\
\hline 6 & $\mathrm{KF}$ & QNSE/QNSE_SF & THOM2 & $\mathrm{TD}$ & DS & RRTM \\
\hline 7 & $\mathrm{KF}$ & MYNN2.5/MON & THOM2 & $\mathrm{TD}$ & DS & RRTM \\
\hline 8 & $\mathrm{KF}$ & MYNN2.5/MYNN_SF & THOM2 & $\mathrm{TD}$ & DS & RRTM \\
\hline 9 & $\mathrm{KF}$ & MYNN3/MYNN_SF & THOM2 & $\mathrm{TD}$ & DS & RRTM \\
\hline 10 & $\mathrm{KF}$ & ACM2/Pleim_SF & THOM2 & $\mathrm{TD}$ & DS & RRTM \\
\hline 11 & $\mathrm{KF}$ & BOULAC/MON & THOM2 & $\mathrm{TD}$ & DS & RRTM \\
\hline \multicolumn{7}{|c|}{ Experiments with microphysics schemes } \\
\hline 12 & $\mathrm{KF}$ & MYNN2.5/MON & KS & $\mathrm{TD}$ & DS & RRTM \\
\hline 13 & $\mathrm{KF}$ & MYNN2.5/MON & LIN & $\mathrm{TD}$ & DS & RRTM \\
\hline 14 & $\mathrm{KF}$ & MYNN2.5/MON & WSM3 & $\mathrm{TD}$ & DS & RRTM \\
\hline 15 & $\mathrm{KF}$ & MYNN2.5/MON & WSM5 & $\mathrm{TD}$ & DS & RRTM \\
\hline 16 & $\mathrm{KF}$ & MYNN2.5/MON & FERRI & $\mathrm{TD}$ & DS & RRTM \\
\hline 17 & $\mathrm{KF}$ & MYNN2.5/MON & WSM6 & $\mathrm{TD}$ & DS & RRTM \\
\hline 18 & $\mathrm{KF}$ & MYNN2.5/MON & GODDARD & $\mathrm{TD}$ & DS & RRTM \\
\hline 19 & $\mathrm{KF}$ & MYNN2.5/MON & MORR & $\mathrm{TD}$ & DS & RRTM \\
\hline 20 & $\mathrm{KF}$ & MYNN2.5/MON & DM5 & $\mathrm{TD}$ & DS & RRTM \\
\hline 21 & $\mathrm{KF}$ & MYNN2.5/MON & DM6 & $\mathrm{TD}$ & DS & RRTM \\
\hline 22 & $\mathrm{KF}$ & MYNN2.5/MON & THOMP & $\mathrm{TD}$ & DS & RRTM \\
\hline \multicolumn{7}{|c|}{ Experiments with surface physics schemes } \\
\hline 23 & $\mathrm{KF}$ & MYNN2.5/MON & KS & NLS & DS & RRTM \\
\hline 24 & $\mathrm{KF}$ & MYNN2.5/MON & KS & RUC & DS & RRTM \\
\hline 25 & $\mathrm{KF}$ & MYNN2.5/MON & KS & PLEIM & DS & RRTM \\
\hline \multicolumn{7}{|c|}{ Experiments with SWR schemes } \\
\hline 26 & $\mathrm{KF}$ & MYNN2.5/MON & KS & RUC & GSW & RRTM \\
\hline 27 & $\mathrm{KF}$ & MYNN2.5/MON & KS & RUC & RRTMG & RRTM \\
\hline \multicolumn{7}{|c|}{ Experiments with LWR schemes } \\
\hline 28 & $\mathrm{KF}$ & MYNN2.5/MON & KS & RUC & RRTMG & RRTM \\
\hline
\end{tabular}

Table 3. Experimental procedure for track prediction. 
longitude of cyclone track in the JTWC observation and WRF simulations, respectively and $n$ is the number of observations and simulation data. The best scheme has been chosen on the basis of both the propagation of simulated track and the RMS errors. Intensity experiments have also been conducted in a fashion analogous to the one described above and the maximum wind $(\mathrm{m} / \mathrm{s})$ at $10 \mathrm{~m}$ height has been obtained from the model output. These are then compared with the JTWC retrieval wind data and the RMS error is then computed. The best scheme is the one that gives the least RMS error.

\section{Results and discussion}

\subsection{Track experiments}

\subsubsection{Experiments with cumulus parameterization}

The cumulus schemes bring out the effect of subgrid scale convection on the grid-resolved

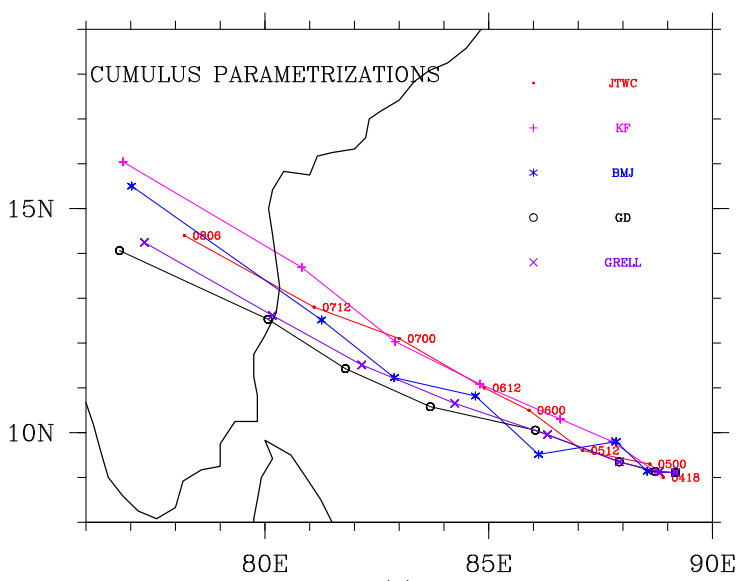

(a)

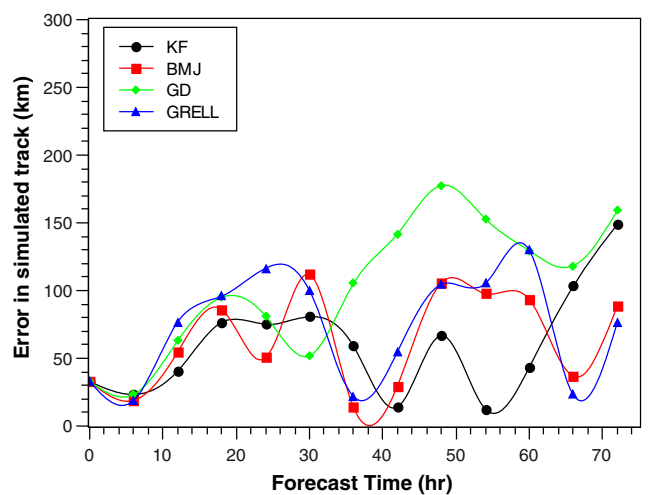

(b)

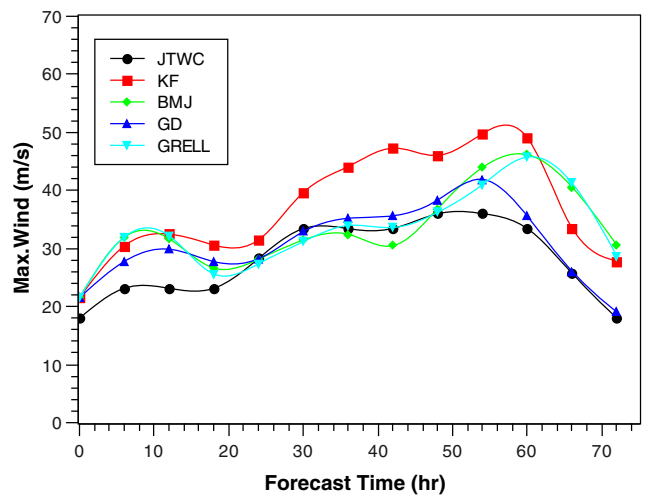

(d)

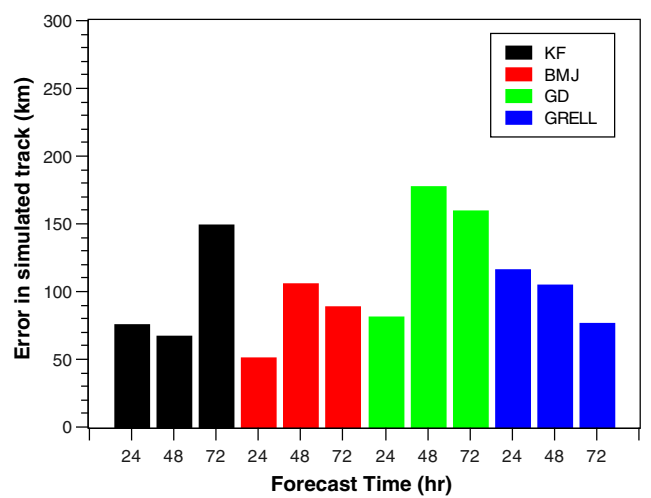

(c)

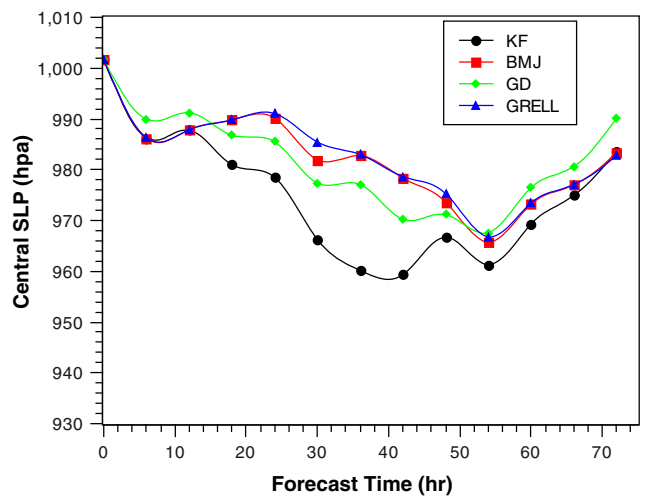

(e)

Figure 2. CPS experiments (a) simulated track propagation, (b) track error with JTWC observations (km), (c) track error (at 24, 48 and 72 hours), (d) time variation of model simulated wind speed $(\mathrm{m} / \mathrm{s})$ and (e) time variation of model simulated $\operatorname{CSLP}(\mathrm{hPa})$. 
Table 4. Track error (km) in cumulus parametrization experiments.

\begin{tabular}{lrrrrrrrrrrrrr}
\hline Time (hr) & 6 & 12 & 18 & 24 & 30 & 36 & 42 & 48 & 54 & 60 & 66 & 72 & $\begin{array}{r}\text { RMS } \\
\text { error }\end{array}$ \\
\hline KF & 23 & 41 & 77 & 75 & 81 & 59 & 14 & 67 & 13 & 43 & 103 & 149 & 73 \\
BMJ & 19 & 55 & 86 & 50 & 112 & 14 & 30 & 106 & 98 & 93 & 37 & 89 & 74 \\
GD & 23 & 63 & 95 & 81 & 52 & 105 & 142 & 178 & 153 & 129 & 118 & 159 & 117 \\
GRELL & 19 & 77 & 96 & 116 & 100 & 22 & 55 & 105 & 105 & 130 & 23 & 76 & 85 \\
\hline
\end{tabular}

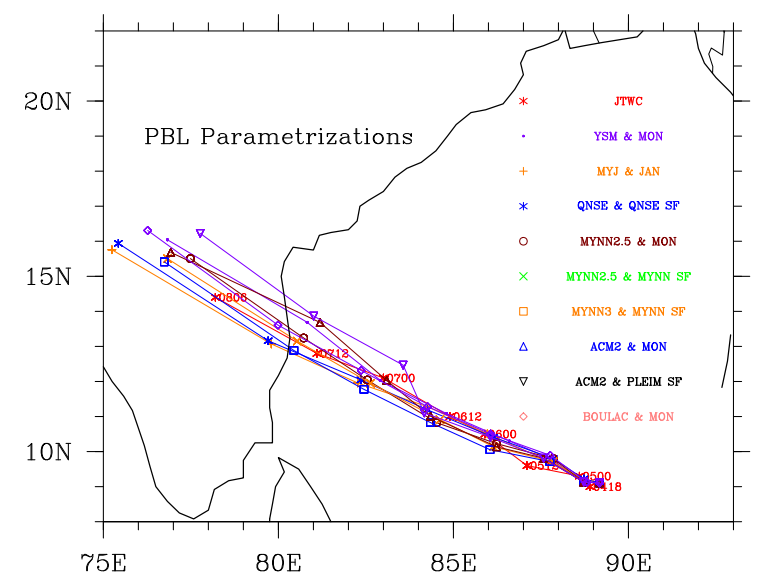

(a)

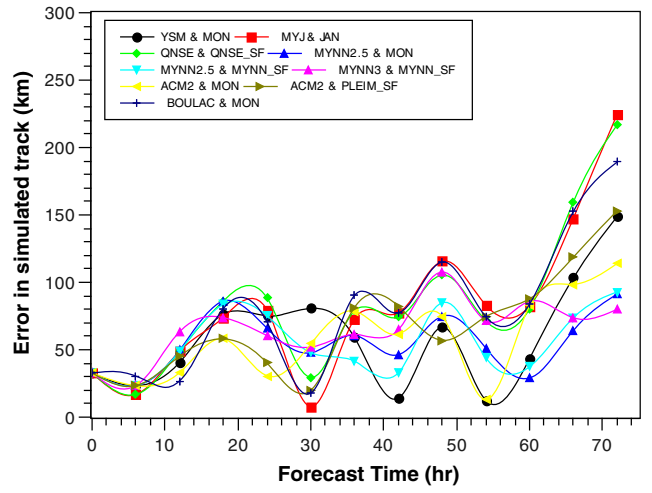

(b)

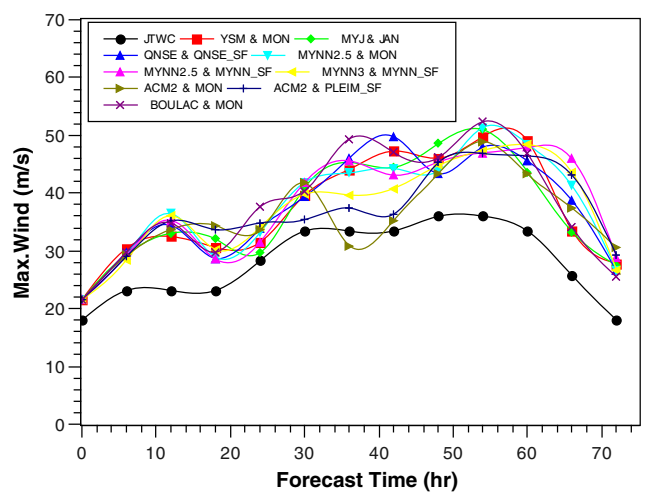

(d)

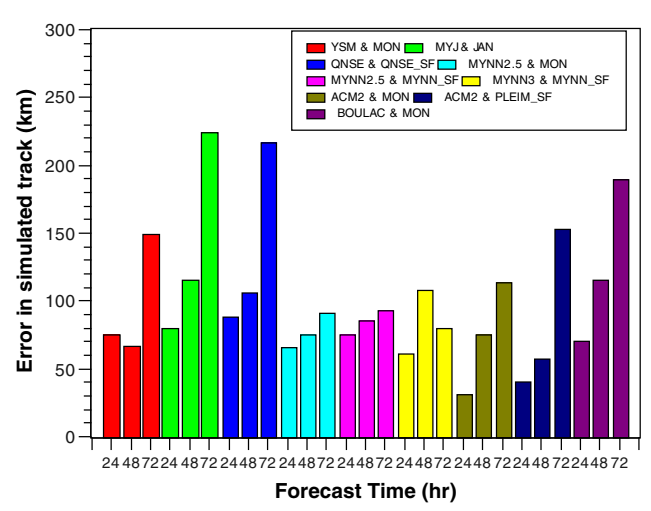

(c)

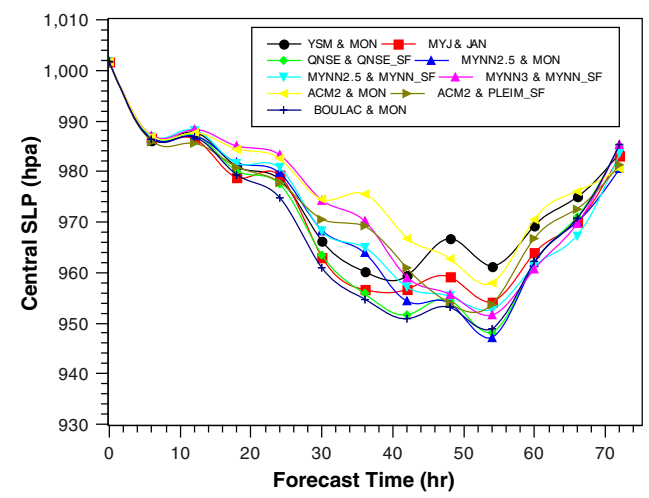

(e)

Figure 3. PBL experiments (a) simulated track propagation, (b) track error with JTWC observations (km), (c) track error (at 24, 48 and 72 hours), (d) time variation of model simulated wind speed $(\mathrm{m} / \mathrm{s})$ and (e) time variation of model simulated $\operatorname{CSLP}(\mathrm{hPa})$. 
thermodynamic variables. In first set of experiments, the effect of various cumulus physics options of the Kain-Fritsch (new Eta) (KF), Betts-MillerJanjic (BMJ), Grell-Devenyi ensemble (GD) and New Grell schemes (GRELL) on the simulations was studied. The tracks of the cyclones simulated with numerical experiments for different cumulus schemes along with the JTWC observation tracks are shown in figure 2(a). All tracks show northwesterly movement of the cyclone. Figure 2(b) shows the track error in the experiments with the four cumulus schemes at 6 hourly intervals and it is seen that the KF scheme has the lowest error with respect to JTWC observations. Figure 2(c) gives the error in the 24, 48 and 72-hr forecasts as a histogram plot. For a 72-hr simulation, the track error is $149 \mathrm{~km}$ in the case of the KF scheme, 89 $\mathrm{km}$ in the case of BMJ scheme, $159 \mathrm{~km}$ in the case of GD and $76 \mathrm{~km}$ in the case of GRELL scheme.

Figure 2(d) shows the wind speeds obtained from the four different simulations and the corresponding JTWC wind data for every 6 hours. From the figure, it is seen that initially all the simulations overpredict the wind speed compared to JTWC wind data. The JTWC data show a maximum wind speed of $36 \mathrm{~m} / \mathrm{s}$ on 7 November 00 UTC. However, the maximum wind speed obtained from simulations is $49.8 \mathrm{~m} / \mathrm{s}$ in the case of KF, $41.9 \mathrm{~m} / \mathrm{s}$ in the case of GD and $46 \mathrm{~m} / \mathrm{s}$ in the case of GRELL on 7 November $00 \mathrm{UTC}$ and $46.16 \mathrm{~m} / \mathrm{s}$ in the case of BMJ on 7 November 06 UTC. The KF, BMJ and GRELL schemes overpredict the storm intensity. The GD scheme predicts a cyclone of moderate intensity that nearly matches with the JTWC data. The intensity of the cyclone from the point of central sea level pressure (CSLP) is generally overpredicted by all the schemes, as can be seen from the time series values given in figure $2(\mathrm{e})$, which are too low for a category storm 1 . The deeping period is about 54 hours in all the cases except the $\mathrm{KF}$ where it is about 42 hours. The KF scheme simulates the cyclone with the lowest CSLP 959 hPa. The BMJ, GD and GRELL also produce strong storms with CSLP of 966, 968 and $967 \mathrm{hPa}$, respectively.

Table 4 shows the track error at six hourly intervals and also the RMS error for a 72-hr forecast. The RMS error value is $73 \mathrm{~km}$ in the case of KF scheme, 74, 117 and $85 \mathrm{~km}$ for the BMJ, GD and GRELL schemes, respectively. Both KF and BMJ schemes produce a lower RMS error compared to the other two schemes. From the four numerical experiments, it is clear that track propagation and RMS error between these four schemes have large variations, and so the track prediction is indeed very sensitive to cumulus parameterization. There is no significant variation in the RMS error between the KF and BMJ schemes but from the point of view of propagation of the track, KF scheme is good. However, it is instructive to mention here that the KF scheme overpredicts the wind speed as $49.76 \mathrm{~m} / \mathrm{s}$, while the JTWC data show a wind speed of $36 \mathrm{~m} / \mathrm{s}$, as given in figure 2(d).

\subsubsection{Effect of PBL and surface layer physics}

The planetary boundary layer (PBL) is responsible for vertical sub-grid-scale fluxes due to eddy transports in the whole atmospheric column. While the surface layer schemes and land surface schemes provide the surface fluxes, the PBL schemes determine the flux profile within the well-mixed boundary layer and the stable layer. The PBL schemes provide the atmospheric 'tendencies' of temperature, moisture (including clouds) and horizontal momentum in the entire atmospheric column (Skamarock 2008). Nine numerical experiments have been conducted with a combination of seven PBL and five surface layer schemes. The best results from the cumulus scheme parameterization experiments namely the KF scheme and the other fixed

Table 5. Track error (km) in PBL experiments.

\begin{tabular}{lrrrrrrrrrrrrr}
\hline Time (hr) & \multicolumn{1}{c}{} & & & & & & & & & & & $\begin{array}{r}\text { RMS } \\
\text { error }\end{array}$ \\
\hline YSU/MON & 23 & 41 & 77 & 75 & 81 & 59 & 14 & 67 & 13 & 43 & 103 & 149 & 73 \\
MYJ/JAN & 17 & 49 & 74 & 79 & 8 & 73 & 77 & 116 & 83 & 82 & 148 & 225 & 102 \\
QNSE/QNSE_SF & 17 & 49 & 86 & 88 & 29 & 79 & 74 & 105 & 71 & 80 & 160 & 217 & 102 \\
MYNN2.5/MON & 23 & 50 & 86 & 66 & 48 & 61 & 46 & 75 & 51 & 29 & 64 & 91 & 61 \\
MYNN2.5/MYNN_SF & 23 & 49 & 84 & 75 & 48 & 42 & 33 & 85 & 44 & 37 & 74 & 93 & 62 \\
MYNN3/MYNN_SF & 23 & 63 & 74 & 60 & 52 & 61 & 65 & 108 & 71 & 86 & 74 & 80 & 71 \\
ACM2/MON & 23 & 33 & 58 & 31 & 54 & 79 & 62 & 75 & 13 & 83 & 99 & 114 & 67 \\
ACM2/Pleim_SF & 23 & 45 & 58 & 40 & 20 & 81 & 82 & 57 & 75 & 88 & 119 & 153 & 79 \\
BOULAC/MON & 31 & 27 & 81 & 70 & 18 & 90 & 77 & 115 & 74 & 84 & 153 & 189 & 97 \\
\hline
\end{tabular}


physics parameterization schemes, as mentioned in table 3 are employed. The propagation of simulated cyclone track for various combinations of PBL and surface layer schemes are presented in figure 3(a). Figure 3(b) shows the track error for all combinations with JTWC observation data and it is seen that the combination of Mellor-Yamada-Nakanishi-Niino 2.5 level TKE scheme (MYNN2.5) for the PBL and the MoninObukhov scheme (MON) for the surface layer parameterization gives the least error with respect to the JTWC observations compared to the other combinations. Track errors at 24, 48, 72 hours are shown in figure 3(c). As expected, for all the cases the track errors increase with forecast time and the $72 \mathrm{hr}$ track error is $80 \mathrm{~km}$ for the case of Mellor-Yamada-Nakanishi-Niino 3 level TKE scheme (MYNN3) for the PBL combined with the Mellor-Yamada-Nakanishi-Niino scheme (MYNN_SF) for the surface layer physics. This

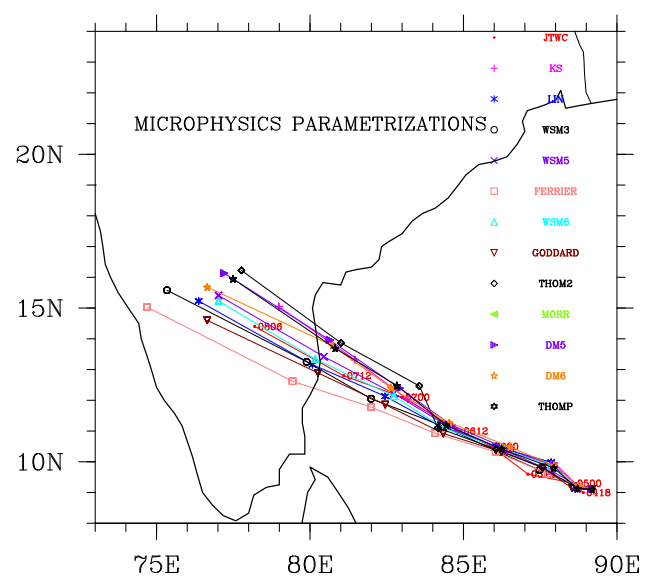

(a)

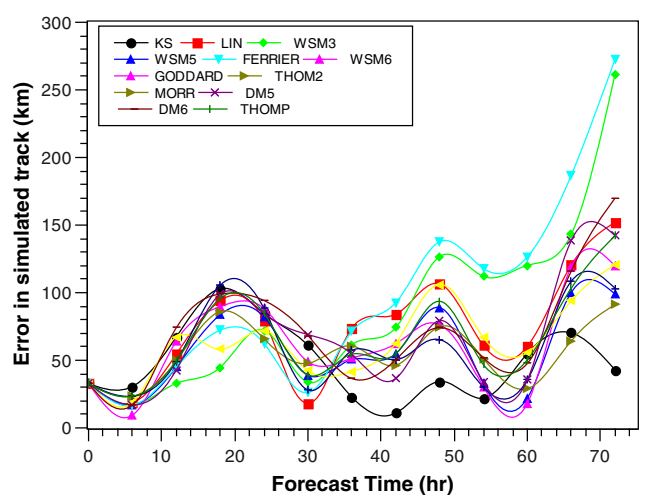

(b)

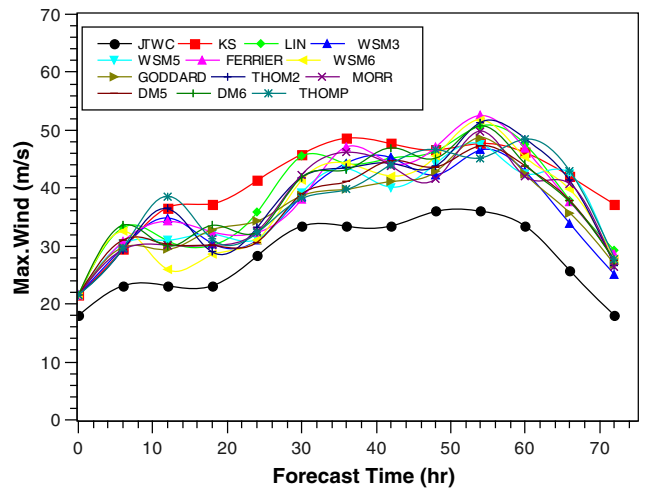

(d)

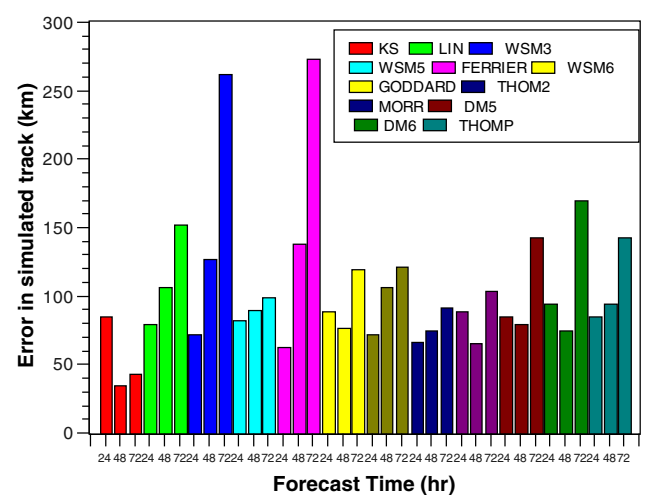

(c)

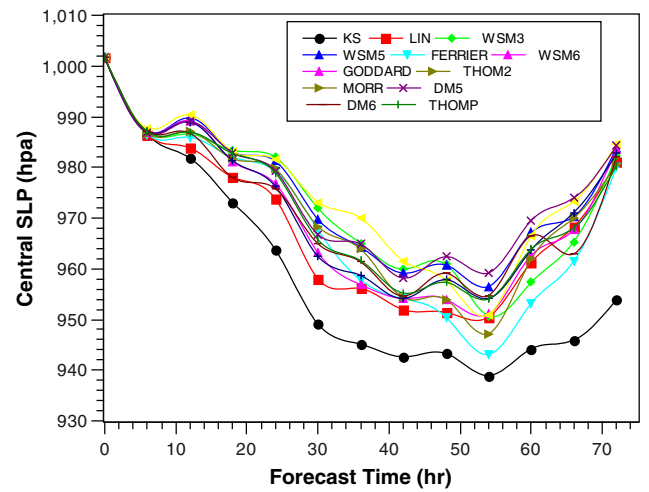

(e)

Figure 4. Microphysics experiments (a) simulated track propagation, (b) track error with JTWC observations (km), (c) track error (at 24, 48 and 72 hours), (d) time variation of model simulated wind speed (m/s) and (e) time variation of model simulated CSLP (hPa). 
gives the lowest error among all the schemes. The maximum error in the $72 \mathrm{hr}$ forecast is $225 \mathrm{~km}$ for the Mellor-Yamada-Janjic (Eta) TKE scheme (MYJ) for the PBL in combination with the Monin-Obukhov (Janjic Eta) scheme (JAN) for the surface layer physics.

Figure $3(\mathrm{~d})$ shows the maximum wind speeds at $10 \mathrm{~m}$ (simulated) height for every six hours. These experiments also indicate that the model 'produces' a strong storm. The maximum wind speed between these combinations varies from 48 to $52 \mathrm{~m} / \mathrm{s}$. All the cases produce a strong cyclone on 7 November 00 UTC except MYNN2.5/MYNN-SF and MYNN2.5/MYNN-SF, which show a strong cyclone on 7 November 06 UTC. The time series of CSLP values shown in figure $3(\mathrm{e})$ also indicate that schemes produce a strong cyclone and the deeping period is $54 \mathrm{hr}$ (up to 7 November 00 UTC) in all the cases except the combination of Yonsei University scheme (YSU) for the PBL and MoninObukhov scheme (MON) for the surface layer, where it is about 42 hours. The $72 \mathrm{hr}$ RMS errors for this set of experiments are reported in table 5 . The RMS values vary between 61 and $102 \mathrm{~km}$. The combination of MYNN2.5 scheme for the PBL and MON scheme for the surface layer produces a smaller RMS error value of $61 \mathrm{~km}$. This also illustrates that the minimum RMS error has been reduced to a value lower than what was possible with the Cumulus parameterization experiments described above. These experiments also indicate that the PBL schemes have a not so insignificant influence on the track prediction. A combination of MYNN2.5 for the PBL and MON for the surface layer produces a track error (72 hr forecast) value of $91 \mathrm{~km}$ and $61 \mathrm{~km}$ for the RMS error. Based on the RMS error and the track propagation errors, the combination of MYNN2.5 and MON can be considered as a good scheme for track prediction.
However, this combination overpredicts the wind speed to be $51.3 \mathrm{~m} / \mathrm{s}$.

\subsubsection{Experiments with microphysics parameterization}

The microphysics (MP) parameterizations explicitly handle water vapour, cloud and precipitation processes and also the microphysical processes of melting of snow, graupel and cloud ice hydrometeors, suppression of falling rain by evaporation. The MP parameterizations can also take into account the falling speed of snow and graupel hydrometeors. In this set of experiments, 12 different MP schemes have been considered along with the KF scheme for the cumulus parameterization and a combination of MYNN2.5/MON schemes for the $\mathrm{PBL} /$ surface layers. The other physics options are kept fixed, as shown in table 3 . The propagation of tracks are shown in figure 4(a). The track errors for different MP schemes along with the JTWC observations as presented in figure 4(b) indicate that the Kessler scheme (KS) and Thompson graupel scheme-2 moment (THMO2) schemes produce a smaller track error as opposed to all other schemes. The maximum track error is $103 \mathrm{~km}$ for the case of KS and $91 \mathrm{~km}$ in the case of THOM2. Table 6 lists the corresponding RMS errors for this set of experiments and the values are $57 \mathrm{~km}$ for the KS and $61 \mathrm{~km}$ for the THOM2 schemes, respectively. While there is no significant variation in RMS error between these two schemes, the $72 \mathrm{hr}$ forecast error (see figure $4(\mathrm{c})$ ) is $43 \mathrm{~km}$ in the case of $\mathrm{KS}$ and $91 \mathrm{~km}$ in case of THOM2. It is seen that the KS scheme produces better track than the THOM2 scheme. Though these two physics options are good for track prediction, both of them overpredict the intensity of the cyclone. From figure 4(d), it is seen that the maximum wind speed is $48.6 \mathrm{~m} / \mathrm{s}$ in $\mathrm{KS}$

Table 6. Track error (km) in microphysics experiments.

\begin{tabular}{|c|c|c|c|c|c|c|c|c|c|c|c|c|c|}
\hline Time (hr) & 6 & 12 & 18 & 24 & 30 & 36 & 42 & 48 & 54 & 60 & 66 & 72 & $\begin{array}{l}\text { RMS } \\
\text { error }\end{array}$ \\
\hline $\mathrm{KS}$ & 31 & 67 & 103 & 85 & 61 & 23 & 11 & 34 & 22 & 55 & 70 & 43 & 57 \\
\hline LIN & 19 & 55 & 94 & 79 & 18 & 74 & 84 & 107 & 61 & 60 & 120 & 152 & 85 \\
\hline WSM3 & 17 & 33 & 45 & 72 & 34 & 62 & 74 & 127 & 112 & 120 & 143 & 262 & 112 \\
\hline WSM5 & 17 & 45 & 84 & 82 & 39 & 51 & 55 & 89 & 33 & 22 & 100 & 99 & 66 \\
\hline Ferrier & 17 & 45 & 72 & 62 & 26 & 71 & 93 & 138 & 118 & 126 & 187 & 273 & 124 \\
\hline WSM6 & 9 & 64 & 90 & 88 & 49 & 52 & 62 & 77 & 30 & 18 & 119 & 120 & 73 \\
\hline GODDARD & 19 & 67 & 58 & 72 & 42 & 42 & 63 & 106 & 67 & 56 & 94 & 121 & 73 \\
\hline THOM2 & 23 & 50 & 86 & 66 & 48 & 61 & 46 & 75 & 51 & 29 & 64 & 91 & 61 \\
\hline MORR & 23 & 49 & 106 & 88 & 28 & 57 & 50 & 66 & 30 & 36 & 108 & 103 & 69 \\
\hline DM5 & 17 & 43 & 99 & 85 & 69 & 55 & 36 & 79 & 34 & 36 & 139 & 142 & 80 \\
\hline DM6 & 17 & 74 & 99 & 94 & 68 & 36 & 50 & 74 & 52 & 48 & 116 & 170 & 85 \\
\hline THOMP & 23 & 50 & 96 & 85 & 39 & 55 & 55 & 94 & 47 & 50 & 103 & 142 & 77 \\
\hline
\end{tabular}




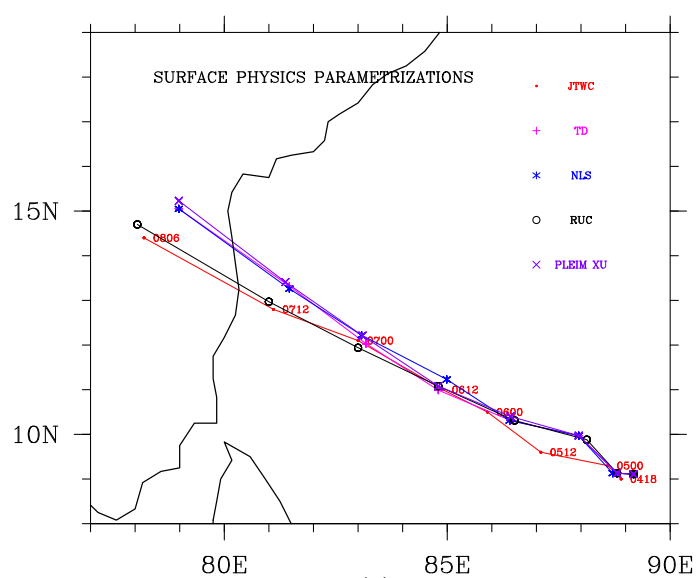

(a)

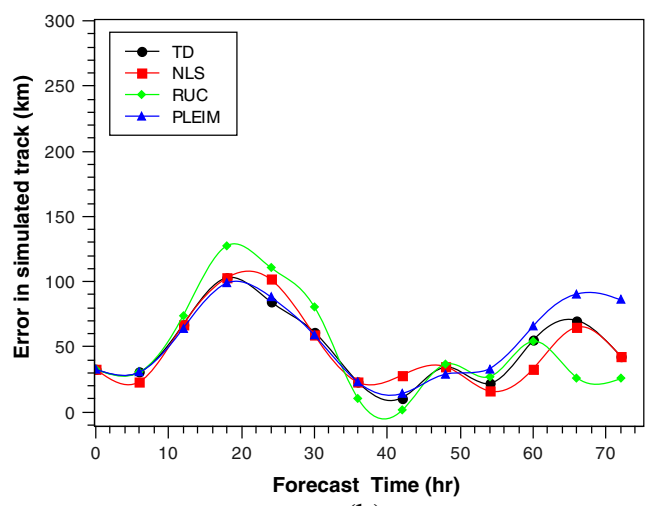

(b)

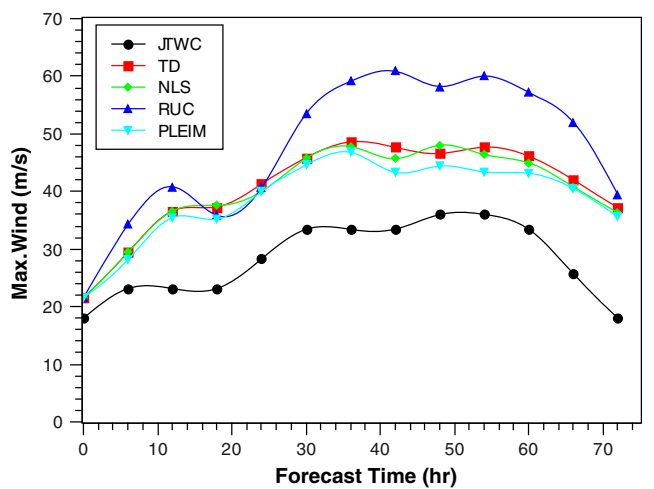

(d)

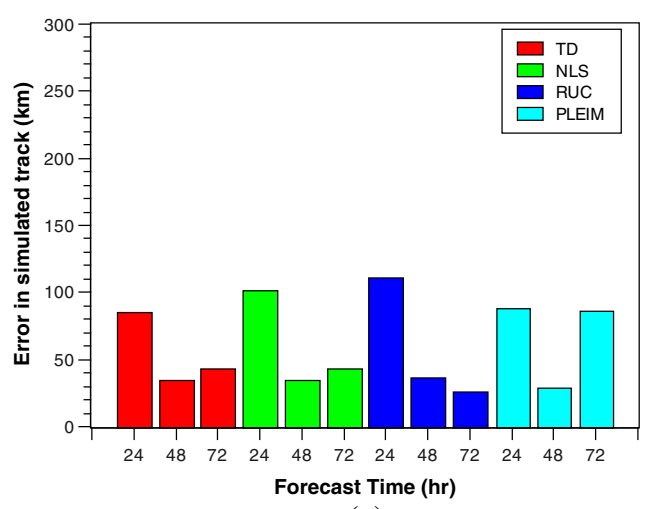

(c)

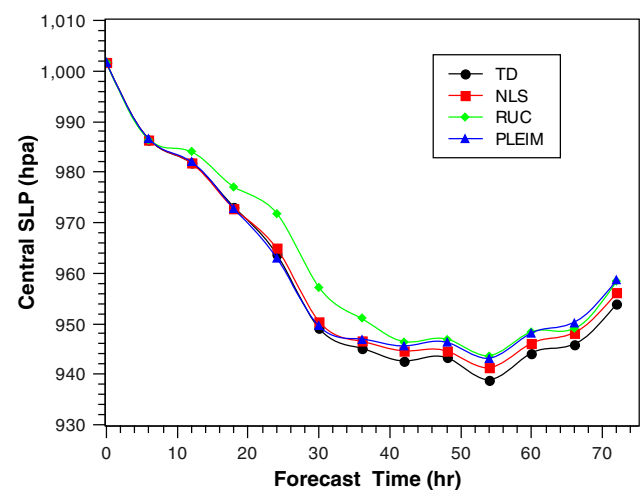

(e)

Figure 5. Land surface model experiments (a) simulated track propagation, (b) track error with JTWC observations (km), (c) track error (at 24, 48 and 72 hours), (d) time variation of model simulated wind speed (m/s) and (e) time variation of model simulated CSLP $(\mathrm{hPa})$.

Table 7. Track error $(\mathrm{km})$ in land surface model experiments.

\begin{tabular}{lrrrrrrrrrrrrr}
\hline Time (hr) & 6 & 12 & 18 & 24 & 30 & 36 & 42 & 48 & 54 & 60 & 66 & 72 & $\begin{array}{c}\text { RMS } \\
\text { error }\end{array}$ \\
\hline TD & 31 & 67 & 103 & 85 & 61 & 23 & 11 & 34 & 22 & 55 & 70 & 43 & 57 \\
NCL & 23 & 67 & 103 & 102 & 59 & 23 & 28 & 35 & 16 & 33 & 65 & 43 & 57 \\
RUC & 31 & 74 & 128 & 111 & 81 & 10 & 1 & 37 & 27 & 54 & 26 & 26 & 63 \\
PLEIM & 31 & 64 & 99 & 88 & 59 & 23 & 14 & 29 & 33 & 66 & 91 & 86 & 64 \\
\hline
\end{tabular}

while it is $51.3 \mathrm{~m} / \mathrm{s}$ in THOM2. Figure $4(\mathrm{e})$ also indicates that these two schemes produce a strong storm in terms of CSLP with the lowest values being
$938.9 \mathrm{hPa}$ from the $\mathrm{KS}$ and $947.2 \mathrm{hPa}$ from the THOM2 on 7 November 00 UTC. This experiment shows that large variations can occur between various 


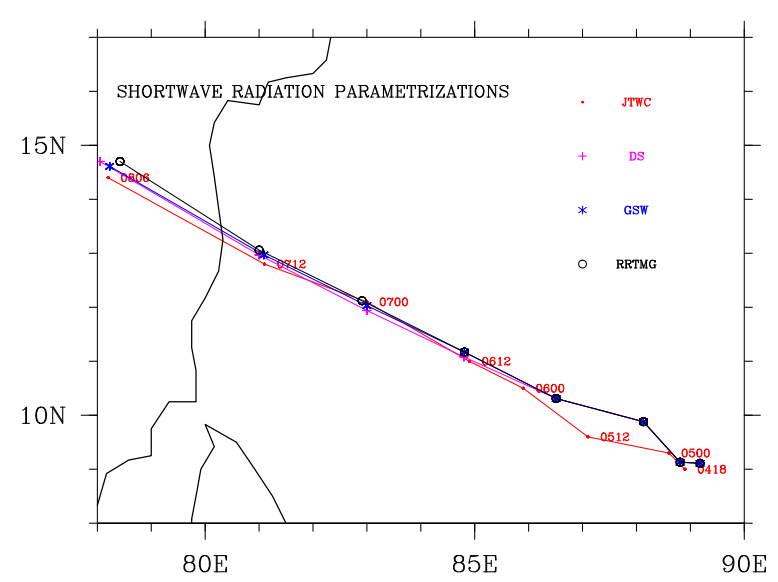

(a)

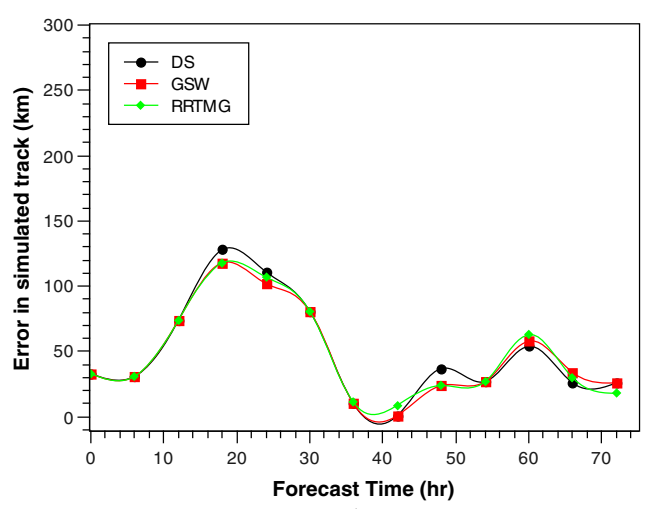

(b)

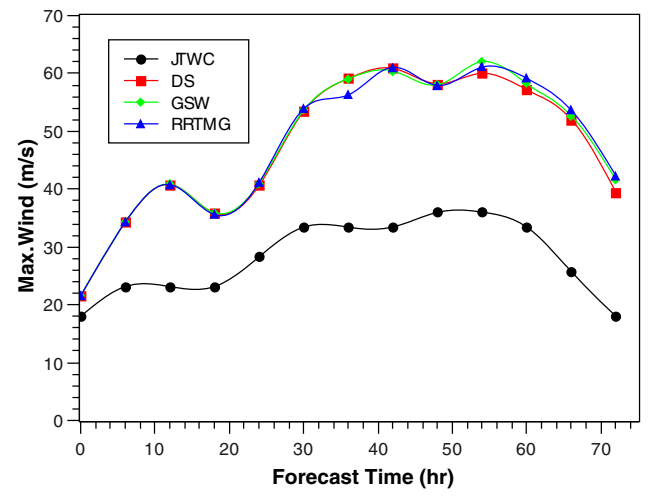

(d)

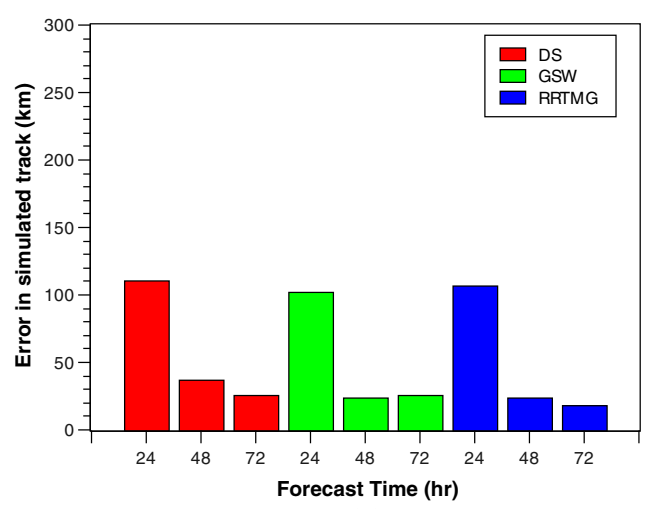

(c)

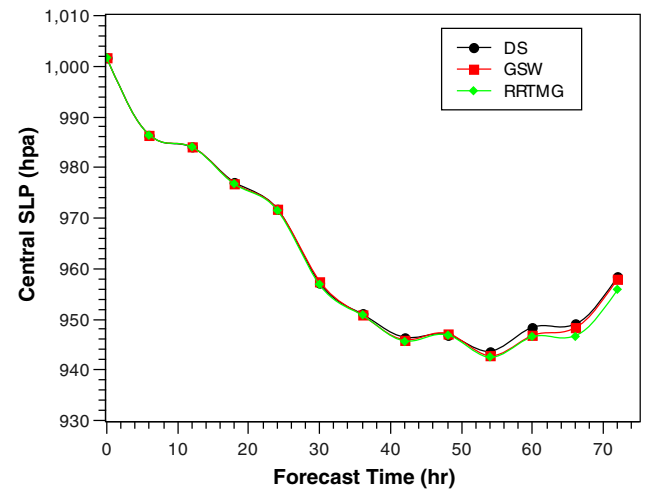

(e)

Figure 6. SWR experiments (a) simulated track propagation, (b) track error with JTWC observations (km), (c) track error (at 24, 48 and 72 hours), (d) time variation of model simulated wind speed $(\mathrm{m} / \mathrm{s})$ and (e) time variation of model simulated CSLP $(\mathrm{hPa})$.

Table 8. Track error $(\mathrm{km})$ in short wave radiation experiments.

\begin{tabular}{lccccccccccccc}
\hline Time (hr) & 6 & 12 & 18 & 24 & 30 & 36 & 42 & 48 & 54 & 60 & 66 & 72 & $\begin{array}{c}\text { RMS } \\
\text { error }\end{array}$ \\
\hline DS & 31 & 74 & 128 & 111 & 81 & 10 & 1 & 37 & 27 & 54 & 26 & 26 & 63 \\
GSW & 31 & 74 & 118 & 102 & 81 & 10 & 1 & 24 & 27 & 58 & 34 & 26 & 60 \\
RRTMG & 31 & 74 & 118 & 107 & 81 & 11 & 9 & 24 & 27 & 63 & 30 & 18 & 61 \\
\hline
\end{tabular}

physics schemes (for example, the RMS error can vary from 57 to $124 \mathrm{~km}$ and the $72 \mathrm{hr}$ forecast error can vary between 43 and $273 \mathrm{~km}$ ). The largest RMS error in this experiment of $124 \mathrm{~km}$ corresponds to the Ferrier (new Eta) microphysics scheme (FERRIER). The results from these experiments indicate that the microphysics can also critically impact the track prediction. 


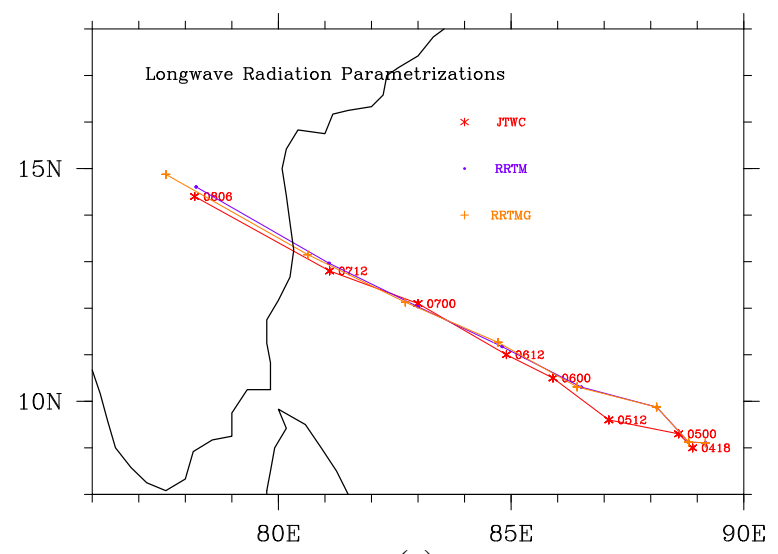

(a)

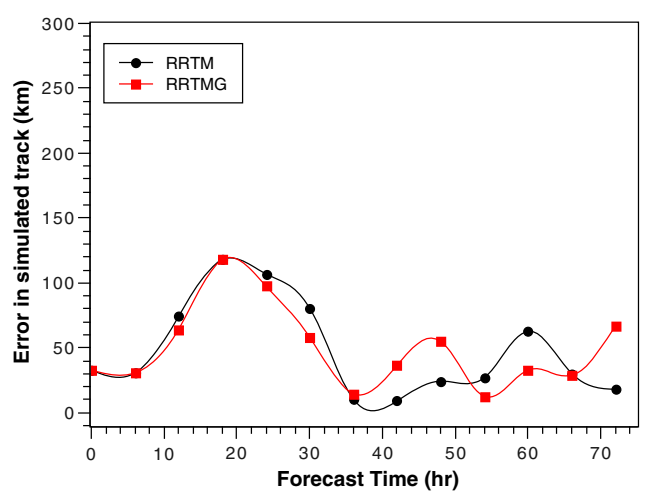

(b)

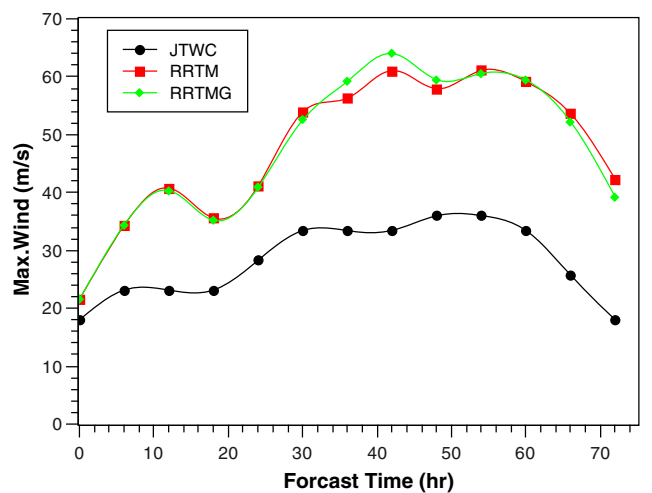

(d)

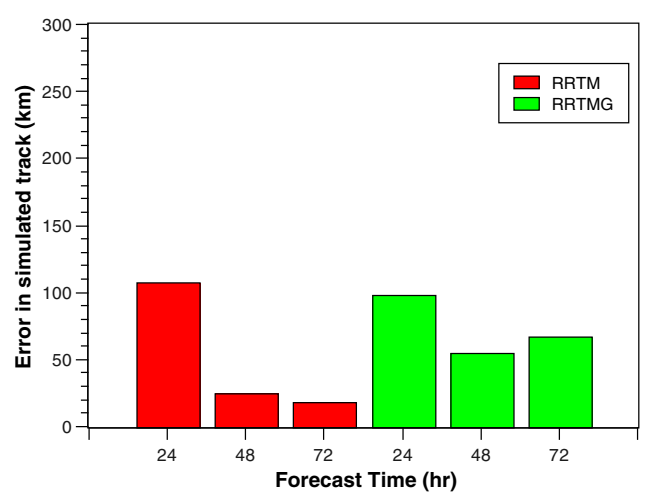

(c)

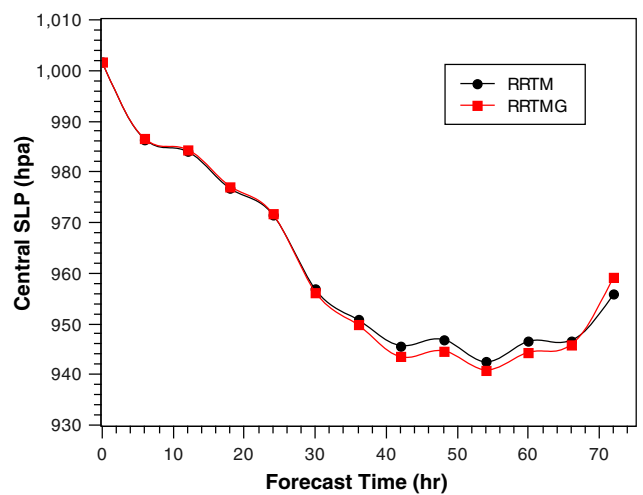

(e)

Figure 7. LWR experiments (a) simulated track propagation, (b) track error with JTWC observations (km), (c) track error (at 24, 48 and 72 hours), (d) time variation of model simulated wind speed $(\mathrm{m} / \mathrm{s})$ and (e) time variation of model simulated $\operatorname{CSLP}(\mathrm{hPa})$.

Table 9. Track error ( $\mathrm{km}$ ) in long wave radiation parameterization experiments.

\begin{tabular}{lccrrrrrrrrrrr}
\hline Time (hr) & 6 & 12 & 18 & 24 & 30 & 36 & 42 & 48 & 54 & 60 & 66 & 72 & $\begin{array}{c}\text { RMS } \\
\text { error }\end{array}$ \\
\hline RRTM & 31 & 74 & 118 & 107 & 81 & 11 & 9 & 24 & 27 & 63 & 30 & 18 & 61 \\
RRTMG & 31 & 64 & 118 & 98 & 58 & 15 & 36 & 55 & 13 & 33 & 29 & 67 & 60 \\
\hline
\end{tabular}

\subsubsection{Experiments with land surface model (LSM)}

The land-surface models (LSMs) are responsible for the thermal and moisture fluxes in multiple layers of the soil and also vegetation, root, canopy effects and surface snow-cover. These models use atmospheric information from the surface layer scheme, radiative forcing from the radiation scheme, and 
Table 10. Best combination of physics schemes for track prediction.

\begin{tabular}{lll}
\hline Sl. no & \multicolumn{1}{c}{ Parameterization } & \multicolumn{1}{c}{ Scheme } \\
\hline 1 & Cumulus parameterization & Kain-Fritsch(new Eta) scheme (KF) \\
2 & PBL & Mellor-Yamada-Nakanishi-Niino 2.5 level \\
& & TKE (MYNN2.5) \\
3 & Microphysics & Kessler scheme (KS) \\
4 & Surface layer physics & Monin-Obukhov scheme (MON) \\
5 & Land surface model & Rapid Update Cycle land-surface \\
& & model (RUC) \\
6 & Long wave radiation physics & Rapid Radiative Transfer Model (RRTM) \\
7 & Short wave radiation physics & Dudhia scheme (DS) \\
\hline
\end{tabular}

Table 11. Experimental procedure for wind prediction.

\begin{tabular}{|c|c|c|c|c|c|c|}
\hline Exp. no. & Cumulus & PBL & Microphysics & Surface physics & SWR & LWR \\
\hline \multicolumn{7}{|c|}{ Experiments with PBL parameterization schemes } \\
\hline 1 & GD & MYJ/JAN & THOM2 & $\mathrm{TD}$ & DS & RRTM \\
\hline 2 & GD & QNSE/QNSE_SF & THOM2 & TD & DS & RRTM \\
\hline 3 & GD & MYNN2.5/MON & THOM2 & TD & DS & RRTM \\
\hline 4 & GD & MYNN2.5/MYNN_SF & THOM2 & $\mathrm{TD}$ & DS & RRTM \\
\hline 5 & GD & MYNN3/MYNN_SF & THOM2 & $\mathrm{TD}$ & DS & RRTM \\
\hline 6 & GD & ACM2/Pleim_SF & THOM2 & TD & DS & RRTM \\
\hline 7 & GD & BOULAC/MON & THOM2 & TD & DS & RRTM \\
\hline \multicolumn{7}{|c|}{ Experiments with microphysics schemes } \\
\hline 8 & GD & MYJ/JAN & $\mathrm{KS}$ & $\mathrm{TD}$ & DS & RRTM \\
\hline 9 & GD & MYJ/JAN & LIN & TD & DS & RRTM \\
\hline 10 & GD & MYJ/JAN & WSM3 & $\mathrm{TD}$ & DS & RRTM \\
\hline 11 & GD & MYJ/JAN & WSM5 & $\mathrm{TD}$ & DS & RRTM \\
\hline 12 & GD & MYJ/JAN & FERRI & $\mathrm{TD}$ & DS & RRTM \\
\hline 13 & GD & MYJ/JAN & WSM6 & TD & DS & RRTM \\
\hline 14 & GD & MYJ/JAN & GODDARD & $\mathrm{TD}$ & DS & RRTM \\
\hline 15 & GD & MYJ/JAN & MORR & TD & DS & RRTM \\
\hline 16 & GD & MYJ/JAN & DM5 & $\mathrm{TD}$ & DS & RRTM \\
\hline 17 & GD & MYJ/JAN & DM6 & $\mathrm{TD}$ & DS & RRTM \\
\hline 18 & GD & MYJ/JAN & THOMP & $\mathrm{TD}$ & DS & RRTM \\
\hline \multicolumn{7}{|c|}{ Experiments with surface physics schemes } \\
\hline 19 & GD & MYJ/JAN & WSM3 & NLS & DS & RRTM \\
\hline 20 & GD & MYJ/JAN & WSM3 & RUC & DS & RRTM \\
\hline 21 & GD & MYJ/JAN & WSM3 & PLEIM & DS & RRTM \\
\hline \multicolumn{7}{|c|}{ Experiments with SWR schemes } \\
\hline 22 & GD & MYJ/JAN & WSM3 & PLEIM & GSW & RRTM \\
\hline 23 & GD & MYJ/JAN & WSM3 & PLEIM & RRTMG & RRTM \\
\hline \multicolumn{7}{|c|}{ Experiments with LWR schemes } \\
\hline 24 & GD & MYJ/JAN & WSM3 & PLEIM & DS & RRTMG \\
\hline
\end{tabular}

Table 12. Maximum sustainable wind error $(\mathrm{m} / \mathrm{s})$ in cumulus experiments.

\begin{tabular}{lcccccccccccrr}
\hline Time (hr) & 6 & 12 & 18 & 24 & 30 & 36 & 42 & 48 & 54 & 60 & 66 & 72 & $\begin{array}{r}\text { RMS } \\
\text { error }\end{array}$ \\
\hline KF & 7.3 & 9.4 & 7.4 & 3.2 & 6.2 & 10.7 & 13.8 & 10.0 & 13.8 & 15.6 & 7.8 & 9.8 & 10.2 \\
BMJ & 8.8 & 8.5 & 3.5 & 0.1 & 1.9 & 1.0 & 2.9 & 0.8 & 7.9 & 12.7 & 14.9 & 12.6 & 8.0 \\
GD & 4.6 & 6.7 & 4.6 & 0.0 & 0.5 & 1.8 & 2.1 & 2.3 & 5.9 & 2.1 & 0.4 & 1.0 & 3.4 \\
GRELL & 8.8 & 9.0 & 2.5 & 0.9 & 2.2 & 0.5 & 0.2 & 0.2 & 5.0 & 12.3 & 15.6 & 10.7 & 7.7 \\
\hline
\end{tabular}


precipitation forcing from the microphysics and convective schemes. Along with above schemes, the LSMs provide heat fluxes and moisture over the land points and sea-ice points and also give the lower boundary condition fluxes to the PBL schemes (Skamarock 2008). In this study, numerical experiments were conducted with four different land surface models along with the best schemes from previous experiments. These four models distinguish land soil inherently. The land soil is divided into five layers in the Thermal diffusion scheme (TD), four in the Unified Noah landsurface model (NLS), six in the Rapid Update
Cycle land-surface model (RUC) and two in the Pleim-Xu scheme (PLEIM). The propagation of simulated tracks presented in figure 5(a) indicates that there are no appreciable differences between the tracks predicted by four schemes till 7 November 00 UTC. However, beyond this time the TD, NLS and PLEIM schemes deviate from the JTWC observations, while the RUC scheme produces a track closer with the JTWC observations. Figure 5(b) also shows that there is no significant variation in the track error for all the cases up to $54 \mathrm{hr}$ (7 November 00 UTC) and thereafter the error increases in all the cases except for the RUC.

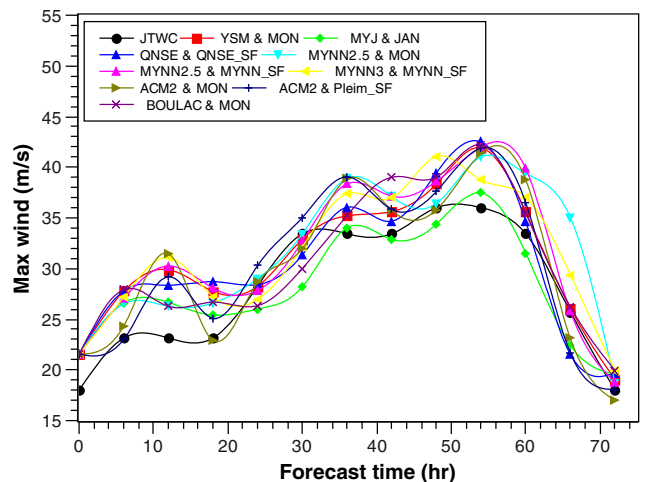

(a)

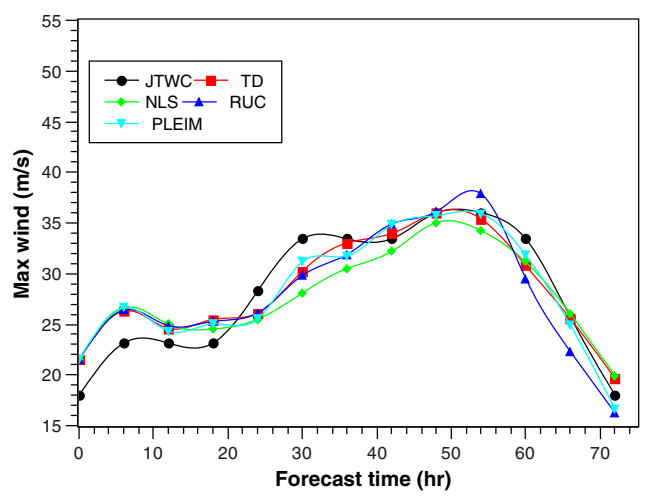

(c)

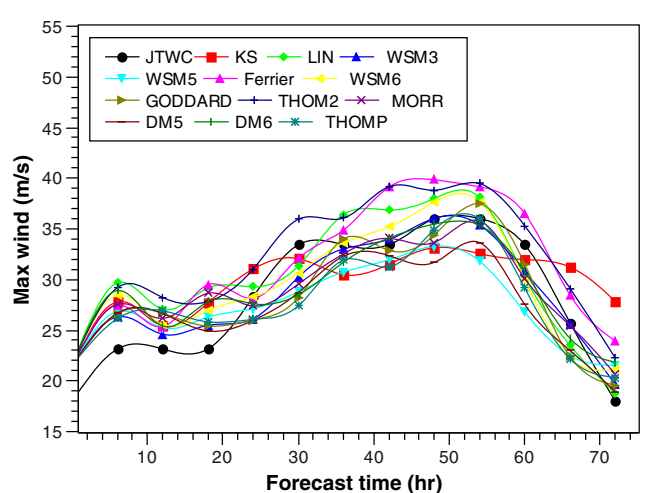

(b)

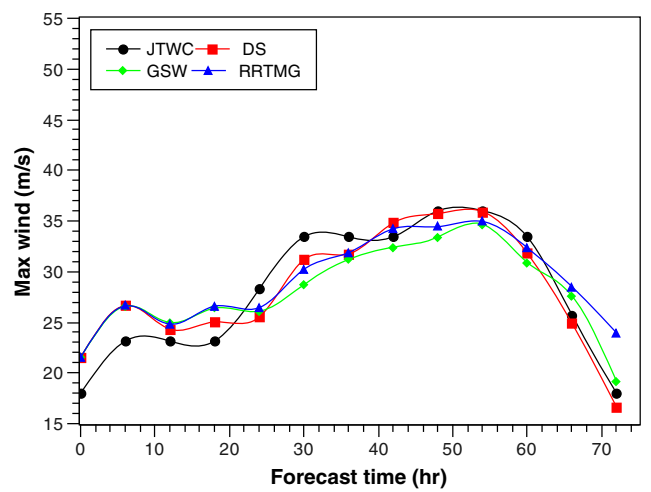

(d)

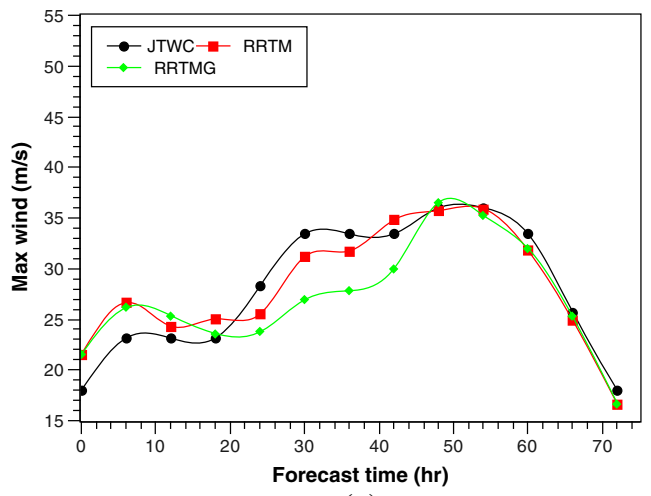

(e)

Figure 8. Time variation of model simulated wind speed for wind experiments (a) PBL, (b) microphysics, (c) land surface model, (d) SWR and (e) LWR. 
The $72 \mathrm{hr}$ track error shown in figure 5(c) clearly highlights that there is no significant difference in the results produced by various schemes. The RMS errors for this set of experiments are listed in table 7. From this table, it is seen that the RMS errors vary between 57 and $64 \mathrm{~km}$. The largest $72 \mathrm{hr}$ forecast error is $86 \mathrm{~km}$ for the case of PLIEM and the lowest is $26 \mathrm{~km}$ for the case of RUC. Based on the RMS, while track propagation is very good with the RUC scheme, it overpredicts the intensity of the cyclone and shows a maximum wind speed of $61 \mathrm{~m} / \mathrm{s}$ (see figure 5(d)). Figure 5(e) also shows that the RUC schemes produces a strong storm with a
CSLP value of $944 \mathrm{hPa}$. From the above results, it is seen that the differences among the schemes is not very significant and one can conclude the track errors are not sensitive to the land surface model.

\subsubsection{Experiments with short wave radiation ( $S W R$ ) schemes}

The radiation schemes in the model provide the atmospheric heating due to radiation flux from the Sun and the SWR schemes handle the process of absorption, reflection and scattering in the atmosphere and from the surface. In this study, numerical

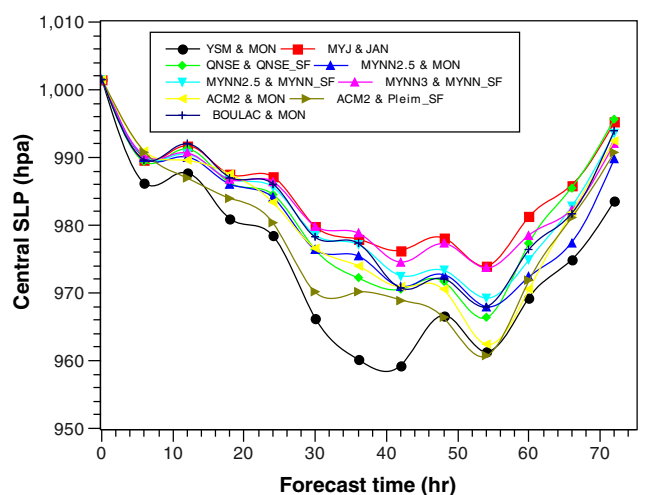

(a)

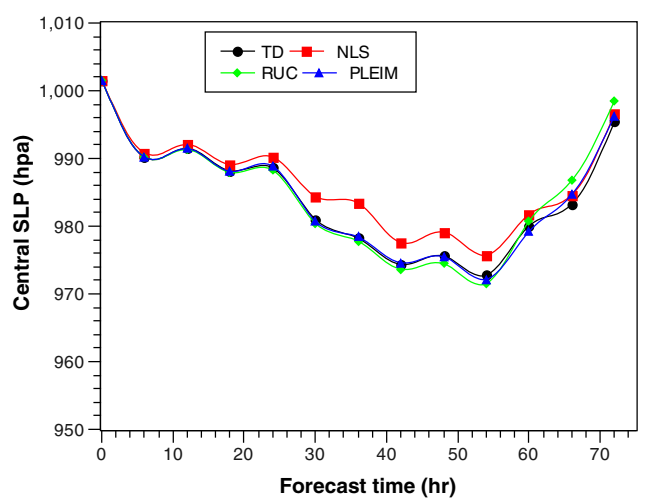

(c)

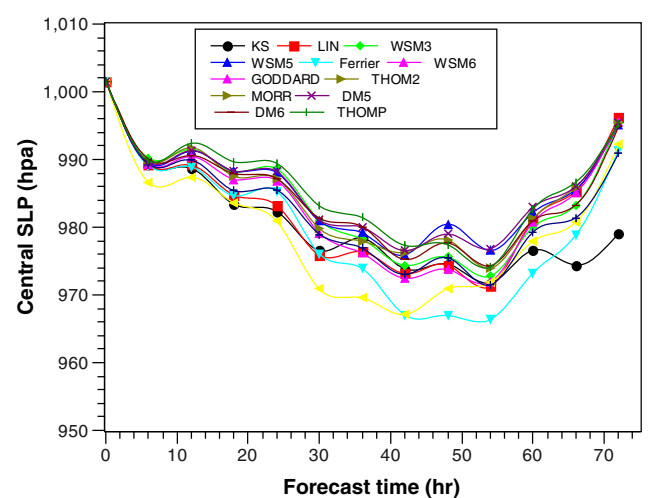

(b)

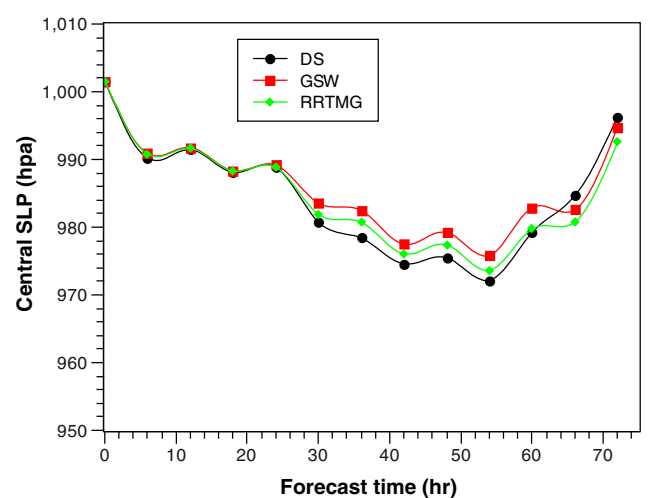

(d)

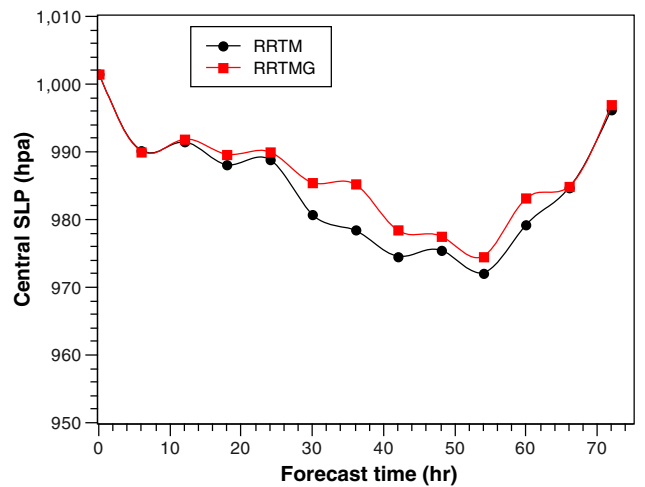

(e)

Figure 9. Time variation of model simulated CSLP (hPa) for wind experiments (a) PBL, (b) microphysics, (c) land surface model, (d) SWR and (e) LWR. 
Table 13. Maximum sustainable wind error $(\mathrm{m} / \mathrm{s})$ in $P B L$ experiments.

\begin{tabular}{lccccccccccccc}
\hline Time (hr) & & & & & & & & & & & \multicolumn{4}{c}{$\begin{array}{c}\text { RMS } \\
\text { error }\end{array}$} \\
\hline YSU/MON & 6 & 12 & 18 & 24 & 30 & 36 & 42 & 48 & 54 & 60 & 66 & 72 & 3.4 \\
MYJ/JAN & 4.6 & 6.7 & 4.6 & 0.0 & 0.5 & 1.8 & 2.2 & 2.3 & 5.9 & 2.1 & 0.4 & 1.0 & 3.4 \\
QNSE/QNSE_SF & 3.5 & 3.5 & 2.3 & 2.3 & 5.2 & 0.6 & 0.6 & 1.6 & 1.5 & 1.9 & 3.3 & 1.6 & 2.7 \\
MYNN2.5/MON & 4.7 & 5.2 & 5.6 & 0.1 & 2.1 & 2.6 & 1.2 & 3.4 & 6.5 & 1.2 & 4.2 & 1.7 & 3.7 \\
MYNN2.5/MYNN_SF & 3.4 & 3.1 & 3.4 & 0.7 & 0.0 & 5.5 & 3.7 & 0.4 & 5.0 & 6.0 & 9.3 & 0.7 & 4.3 \\
MYNN3/MYNN_SF & 4.0 & 7.9 & 4.9 & 0.5 & 0.8 & 4.9 & 3.7 & 2.6 & 6.0 & 6.4 & 0.1 & 0.8 & 4.2 \\
ACM2/MON & 1.2 & 8.3 & 0.2 & 0.4 & 1.5 & 5.4 & 2.3 & 0.2 & 5.3 & 5.3 & 2.6 & 1.0 & 3.8 \\
ACM2/Pleim_SF & 0.1 & 6.0 & 1.9 & 2.0 & 1.6 & 5.6 & 2.4 & 1.6 & 5.9 & 3.1 & 4.0 & 0.1 & 3.5 \\
BOULAC/MON & 4.8 & 3.1 & 3.5 & 1.9 & 3.4 & 1.8 & 5.6 & 3.0 & 6.2 & 2.0 & 0.5 & 1.9 & 3.5 \\
\hline
\end{tabular}

Table 14. Maximum sustainable wind error $(\mathrm{m} / \mathrm{s})$ in microphysics experiments.

\begin{tabular}{lccccccccccccc}
\hline Time (hr) & 6 & 12 & 18 & 24 & 30 & 36 & 42 & 48 & 54 & 60 & 66 & 72 & $\begin{array}{c}\text { RMS } \\
\text { error }\end{array}$ \\
\hline KS & 4.7 & 2.3 & 4.5 & 2.8 & 1.4 & 3.0 & 1.9 & 2.9 & 3.4 & 1.5 & 5.5 & 9.9 & 4.3 \\
LIN & 6.5 & 3.9 & 6.0 & 1.0 & 2.1 & 3.0 & 3.4 & 2.0 & 2.1 & 3.1 & 2.2 & 0.8 & 3.5 \\
WSM3 & 3.2 & 1.4 & 2.3 & 2.2 & 3.2 & 0.4 & 0.5 & 0.0 & 0.6 & 2.6 & 0.2 & 1.7 & 1.9 \\
WSM5 & 3.7 & 2.1 & 3.1 & 1.2 & 4.6 & 2.7 & 1.5 & 2.7 & 4.2 & 6.6 & 3.2 & 3.5 & 3.6 \\
Ferrier & 4.3 & 2.2 & 6.3 & 0.2 & 1.3 & 1.4 & 5.7 & 3.8 & 3.1 & 3.1 & 2.7 & 5.9 & 3.8 \\
WSM6 & 5.3 & 2.4 & 3.8 & 0.0 & 2.8 & 0.2 & 1.8 & 1.7 & 1.7 & 3.4 & 3.5 & 3.2 & 2.9 \\
GODDARD & 3.5 & 3.5 & 2.3 & 2.3 & 5.2 & 0.6 & 0.6 & 1.6 & 1.5 & 1.9 & 3.3 & 1.6 & 2.7 \\
THOM2 & 6.1 & 5.1 & 4.7 & 2.7 & 2.5 & 2.6 & 5.7 & 2.8 & 3.5 & 1.9 & 3.4 & 4.3 & 4.0 \\
MORR & 4.4 & 3.0 & 5.5 & 0.9 & 3.9 & 0.9 & 0.6 & 2.3 & 0.2 & 3.3 & 0.2 & 2.7 & 2.9 \\
DM5 & 3.6 & 3.5 & 1.8 & 2.3 & 4.7 & 1.1 & 1.1 & 4.3 & 2.4 & 5.9 & 2.7 & 0.9 & 3.2 \\
DM6 & 5.8 & 2.3 & 4.7 & 0.7 & 4.9 & 1.7 & 0.7 & 0.6 & 0.6 & 2.6 & 1.5 & 3.8 & 3.1 \\
THOMP & 3.0 & 3.8 & 2.7 & 2.2 & 6.0 & 1.5 & 2.2 & 1.1 & 0.0 & 4.3 & 3.5 & 2.3 & 3.1 \\
\hline
\end{tabular}

Table 15. Maximum sustainable wind error $(\mathrm{m} / \mathrm{s})$ in land surface model experiments.

\begin{tabular}{lccccccccccccc}
\hline Time (hr) & 6 & 12 & 18 & 24 & 30 & 36 & 42 & 48 & 54 & 60 & 66 & 72 & $\begin{array}{c}\text { RMS } \\
\text { error }\end{array}$ \\
\hline TD & 3.2 & 1.4 & 2.3 & 2.2 & 3.2 & 0.4 & 0.5 & 0.0 & 0.6 & 2.6 & 0.2 & 1.7 & 1.9 \\
NLS & 3.5 & 1.9 & 1.4 & 2.8 & 5.3 & 2.9 & 1.2 & 1.0 & 1.8 & 2.3 & 0.3 & 1.9 & 2.5 \\
RUC & 3.3 & 1.7 & 2.2 & 2.2 & 3.6 & 1.5 & 1.5 & 0.1 & 1.9 & 3.9 & 3.4 & 1.7 & 2.5 \\
PLEIM & 3.5 & 1.2 & 1.9 & 2.8 & 2.3 & 1.7 & 1.4 & 0.3 & 0.1 & 1.6 & 0.8 & 1.4 & 1.8 \\
\hline
\end{tabular}

Table 16. Maximum sustainable wind error $(\mathrm{m} / \mathrm{s})$ in short wave radiation experiments.

\begin{tabular}{lccccccccccccc}
\hline Time (hr) & 6 & 12 & 18 & 24 & 30 & 36 & 42 & 48 & 54 & 60 & 66 & 72 & $\begin{array}{c}\text { RMS } \\
\text { error }\end{array}$ \\
\hline DS & 3.5 & 1.2 & 1.9 & 2.8 & 2.3 & 1.7 & 1.4 & 0.3 & 0.1 & 1.6 & 0.8 & 1.4 & 1.8 \\
GSW & 3.5 & 1.8 & 3.3 & 2.2 & 4.7 & 2.2 & 1.0 & 2.6 & 1.3 & 2.5 & 1.9 & 1.2 & 2.6 \\
RRTMG & 3.5 & 1.7 & 3.5 & 1.8 & 3.2 & 1.6 & 0.8 & 1.6 & 1.1 & 1.1 & 2.8 & 5.9 & 2.8 \\
\hline
\end{tabular}

Table 17. Maximum sustainable wind error $(\mathrm{m} / \mathrm{s})$ in long wave radiation experiments.

\begin{tabular}{lccccccccccccc}
\hline Time (hr) & 6 & 12 & 18 & 24 & 30 & 36 & 42 & 48 & 54 & 60 & 66 & 72 & $\begin{array}{c}\text { RMS } \\
\text { error }\end{array}$ \\
\hline RRTM & 3.5 & 1.2 & 1.9 & 2.8 & 2.3 & 1.7 & 1.4 & 0.3 & 0.1 & 1.6 & 0.8 & 1.4 & 1.8 \\
RRTMG & 3.0 & 2.2 & 0.5 & 4.5 & 6.5 & 5.6 & 3.4 & 0.5 & 0.8 & 1.4 & 0.4 & 1.3 & 3.2 \\
\hline
\end{tabular}


Table 18. Best combination of physics schemes for wind prediction.

\begin{tabular}{lll}
\hline Sl. no. & \multicolumn{1}{c}{ Parameterization } & \multicolumn{1}{c}{ Scheme } \\
\hline 1 & Cumulus parameterization & Grell-Devenyi ensemble scheme (GD) \\
2 & PBL & $\begin{array}{c}\text { Mellor-Yamada-Janjic(Eta) TKE } \\
\text { scheme (MYJ) } \\
\end{array}$ \\
3 & Microphysics & WRF Single Moment 3-class simple ice \\
& & scheme (WSM3) \\
4 & Surface layer physics & Monin-Obukhov (Janjic Eta) \\
& & scheme (JAN) \\
5 & Land surface model & Pleim-Xu scheme (PLEIM) \\
6 & Long wave radiation physics & Rapid Radiative Transfer Model (RRTM) \\
7 & Short wave radiation physics & Rapid Radiative Transfer Model for \\
& & Global (RRTMG) \\
\hline
\end{tabular}

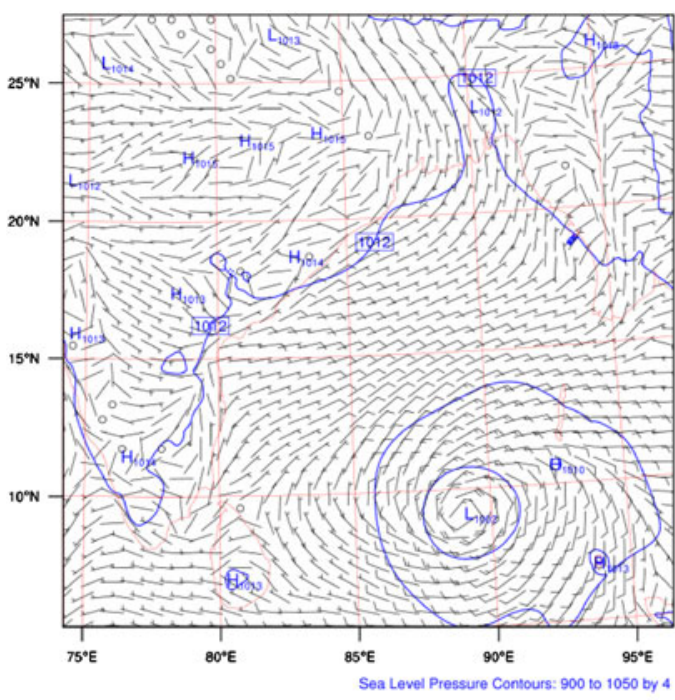

(a)

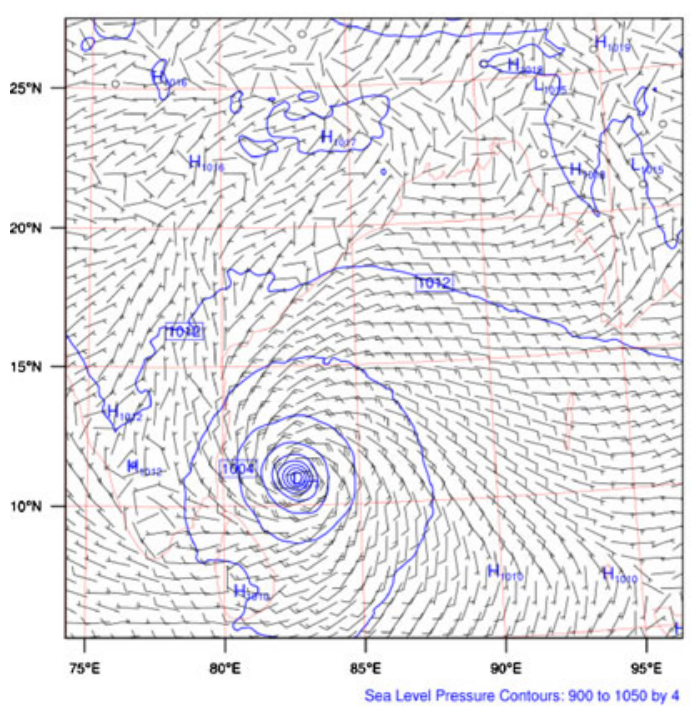

(c)

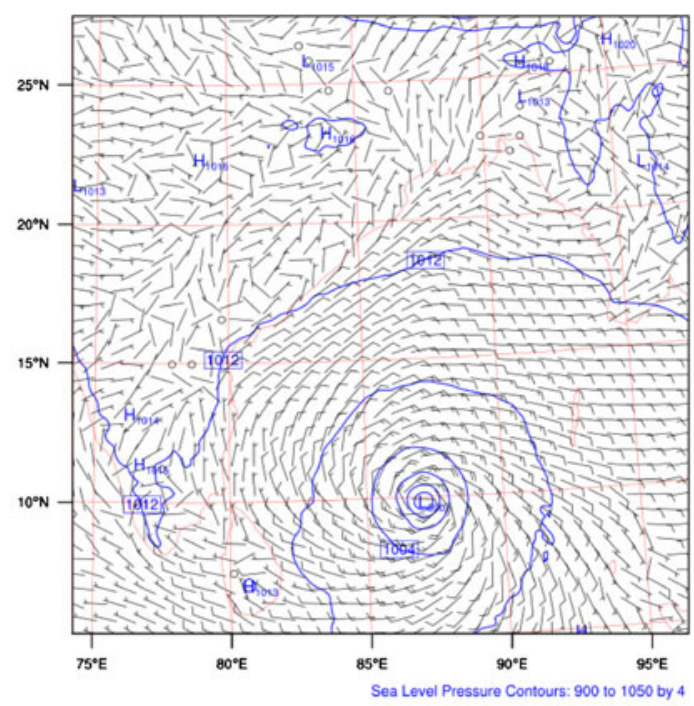

(b)

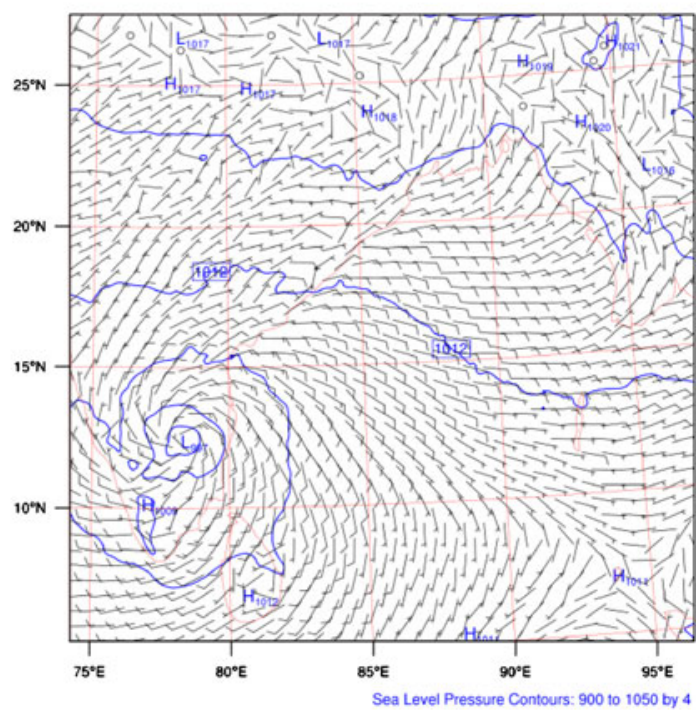

(d)

Figure 10. SLP and wind vectors at various instants of time (a) 4 November 18 UTC, (b) 5 November 18 UTC, (c) 6 November 18 UTC and (d) 7 November 18 UTC. 
experiments were conducted with three different SWR schemes with the other physics schemes held fixed as given in table 3. From figure 6(a), it is seen that the propagation of simulated tracks closely follows the JTWC observations. It is also seen that there is little to choose among the three schemes and figure 6(b) also confirms that. Table 8 lists out the RMS errors associated with the three schemes and all three of them are around $60 \mathrm{~km}$. While there is no significant difference in the RMS errors associated with the schemes, the error in a $72 \mathrm{hr}$ forecast is $18 \mathrm{~km}$ for the case of the Rapid Radiative Transfer Model for Global (RRTMG) but is $26 \mathrm{~km}$ for the other two schemes, as seen in figure 6(c). This indicates that the RRTMG scheme is good for track prediction. Figure 6(d) shows that all the schemes produce a strong cyclone with the maximum wind speed being $62 \mathrm{~m} / \mathrm{s}$ for the case RRTMG scheme and $61 \mathrm{~m} / \mathrm{s}$ for the other two

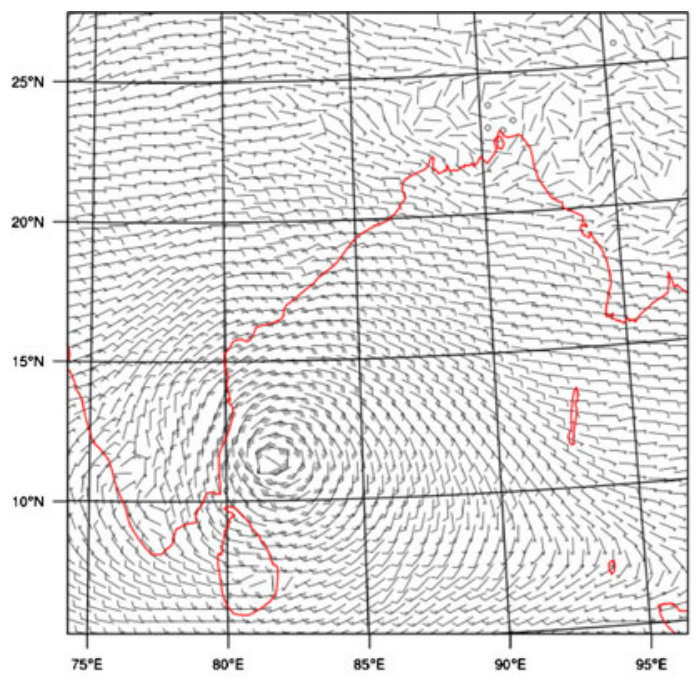

(a) $900 \mathrm{hPa}$

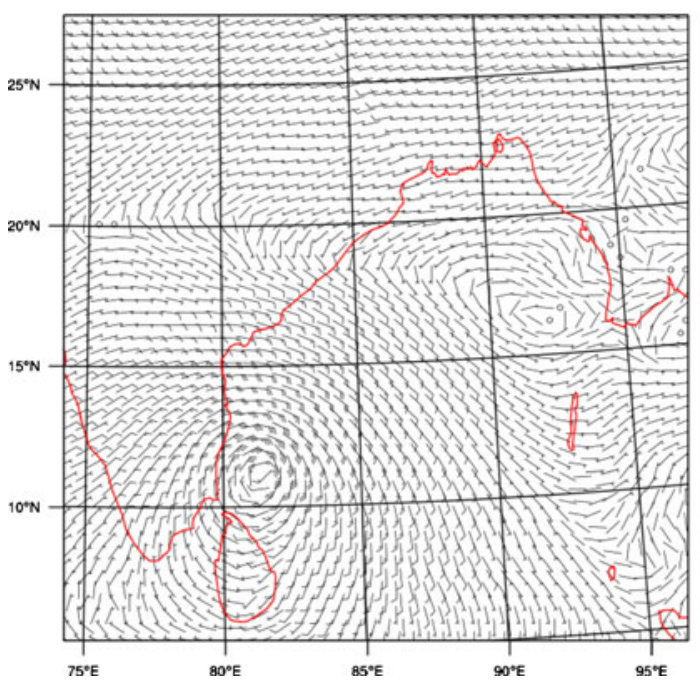

(c) $500 \mathrm{hPa}$ schemes. From figure 6(e) too, it can be inferred that all the three schemes overpredict the intensity. The lowest value of CSLP is $942 \mathrm{hPa}$ for the RRTMG scheme, $943 \mathrm{hPa}$ for the GSW and $944 \mathrm{hPa}$ in case of DS scheme.

\subsubsection{Experiments with long wave radiation (LWR) schemes}

The LWR schemes handle the process of absorption and emission of infrared or thermal radiation by gases and surfaces. Simulations are carried out for two different LWR along with the best schemes determined from previous numerical experiments. Figure 7(a) shows the results for the track propagation and it is seen that both the schemes produce a good match with the JTWC observation track. The Rapid Radiative Transfer Model (RRTM) scheme

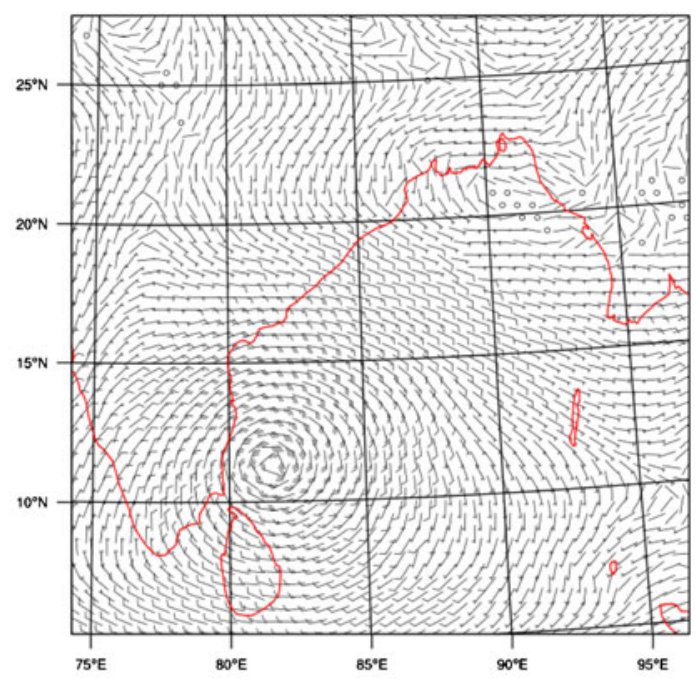

(b) $700 \mathrm{hPa}$

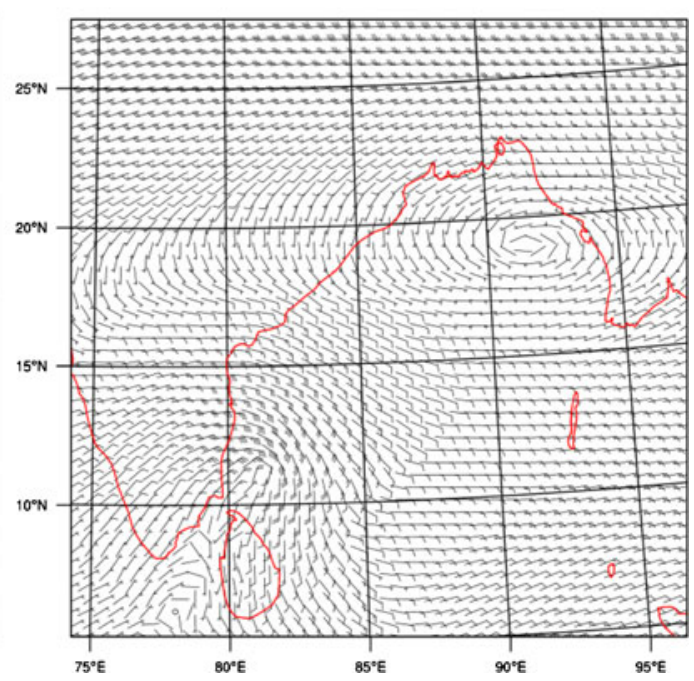

(d) $300 \mathrm{hPa}$

Figure 11. Wind vectors at various pressure levels for cyclone Jal on 7 November 00 UTC. 
produces a better track than the RRTMG scheme. Figure 7(b) shows the track error for the two schemes and indicates that the maximum error is around $118 \mathrm{~km}$ in both the cases. The $72 \mathrm{hr}$ forecast track error is shown in figure $7(\mathrm{c})$ and it is seen that the error is $18 \mathrm{~km}$ for the RRTM scheme, while it is $67 \mathrm{~km}$ for the RRTMG. The RMS errors for this set of experiments is listed in table 9 . It is seen that there is no appreciable difference in the RMS errors associated with the two schemes. The RRTM schemes produce a good track compared to the RRTMG. However, figure 7(d) indicates that the scheme overpredicts the maximum wind speed as $61 \mathrm{~m} / \mathrm{s}$ which is further corroborated by the rather low CSLP value of $942 \mathrm{hPa}$ (see figure 7(e)).

\subsection{Wind experiments}

The first set of experiments which were discussed in the preceding section resulted in the best combination of physics schemes for track prediction which is
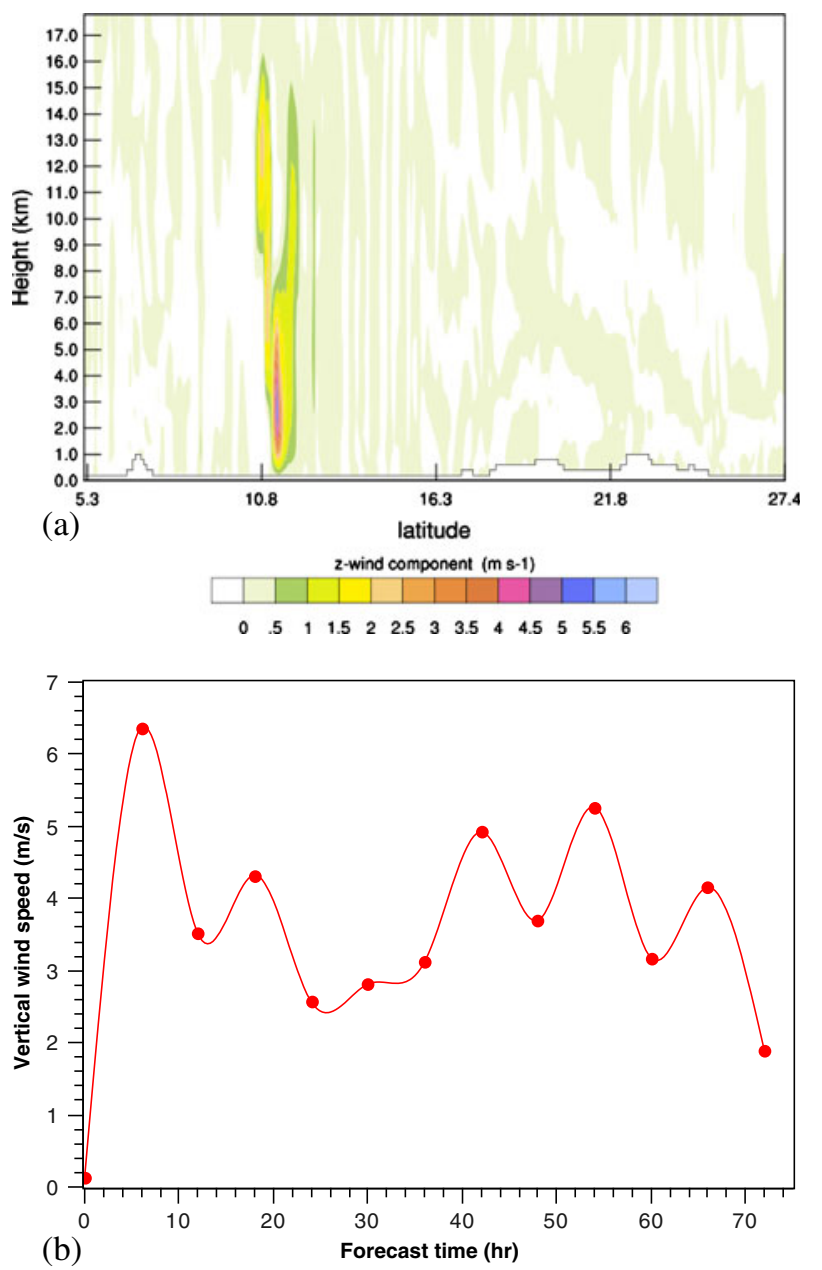

Figure 12. Vertical wind in $\mathrm{m} / \mathrm{s}$ for cyclone Jal at 7 November $00 \mathrm{UTC}$ (a) cross section view along $82^{\circ} \mathrm{E}$ and (b) time variation of model simulated vertical wind. listed in table 10. However, it needs to be reiterated that this 'best' set overpredicts the intensity of the cyclone. So carrying out another set of experiments for determining the best combination of physics schemes for accurate prediction of maximum sustained wind speed becomes imperative. The second

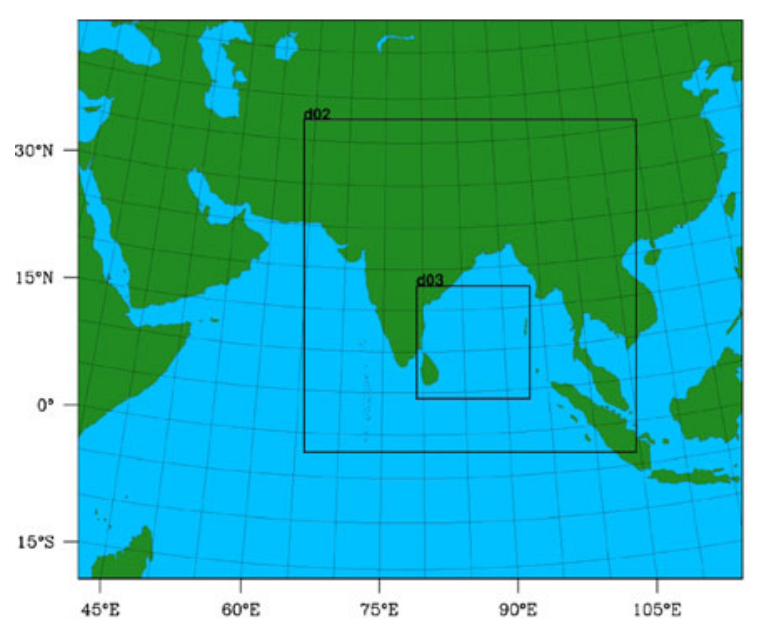

(a)

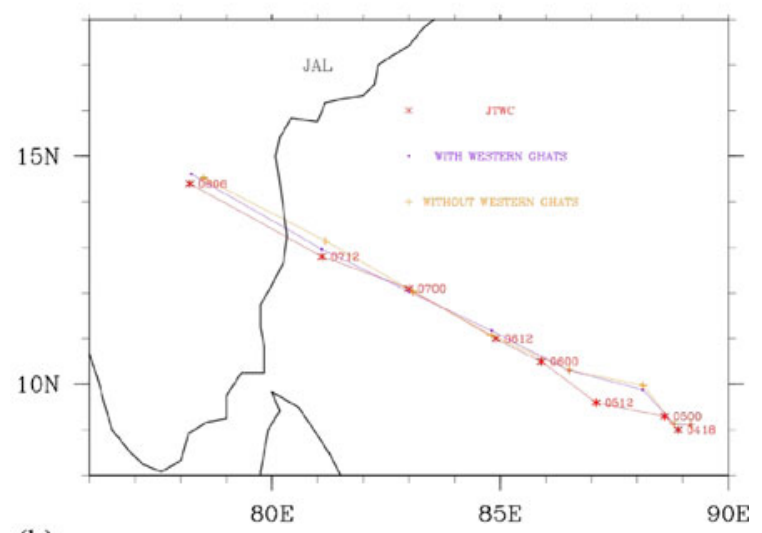

(b)

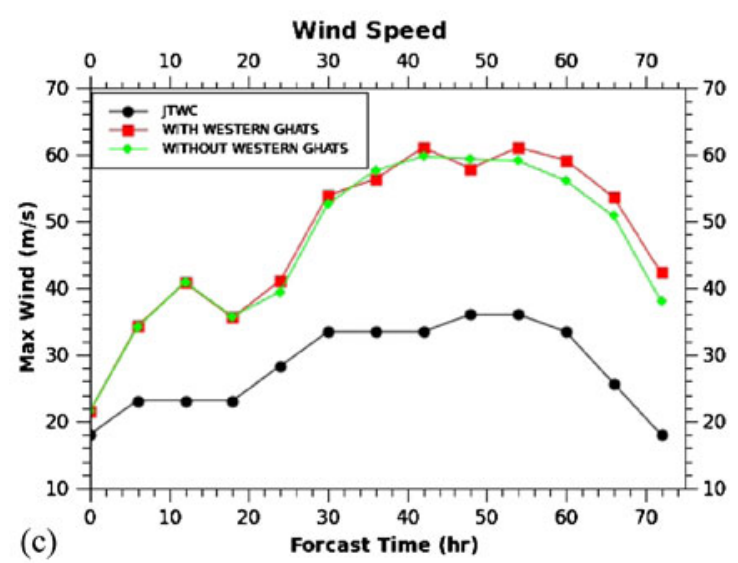

Figure 13. Orography experiments (a) model domain, (b) simulated track propagation and (c) time variation of model simulated wind speed. 
Table 19. Comparison of track error (km) in orography experiments.

\begin{tabular}{lrrrrrrrrrrrrr}
\hline Time (hr) & 6 & 12 & 18 & 24 & 30 & 36 & 42 & 48 & 54 & 60 & 66 & 72 & $\begin{array}{c}\text { RMS } \\
\text { error }\end{array}$ \\
\hline With Western Ghats & 31 & 74 & 118 & 107 & 81 & 11 & 9 & 24 & 27 & 63 & 30 & 18 & 61 \\
Without Western Ghats & 31 & 64 & 121 & 88 & 71 & 15 & 14 & 35 & 13 & 35 & 39 & 46 & 55 \\
\hline
\end{tabular}

Table 20. Comparison of wind error $(\mathrm{m} / \mathrm{s})$ in orography experiments.

\begin{tabular}{lccccccccccccc}
\hline Time (hr) & 6 & 12 & 18 & 24 & 30 & 36 & 42 & 48 & 54 & 60 & 66 & 72 & $\begin{array}{c}\text { RMS } \\
\text { error }\end{array}$ \\
\hline With Western Ghats & 11 & 18 & 12 & 13 & 20 & 23 & 28 & 22 & 25 & 26 & 28 & 24 & 21.5 \\
Without Western Ghats & 11 & 18 & 13 & 11 & 19 & 24 & 26 & 23 & 23 & 23 & 25 & 20 & 20.3 \\
\hline
\end{tabular}

set of experiments is conducted in a manner similar to the first one with available physics options listed in table 1 and the procedure is given in table 11 . The four CPS schemes common for both the experiments show that the Grell-Devenyi ensemble scheme (GD) produces good results compared to the other three schemes, in terms of intensity prediction. The maximum wind speed in this scheme is $42 \mathrm{~m} / \mathrm{s}$ and the lowest CSLP is $967 \mathrm{hPa}$ on 7 November 00 UTC. Table 12 presents the RMS errors of wind speed prediction. The RMS error for the GD scheme is $3.4 \mathrm{~m} / \mathrm{s}$ and it is very low compared to the other schemes.

The wind speed and CSLP simulations for the PBL scheme experiments are shown in figures 8(a) and 9 (a) respectively. From these figures, it can be inferred that the combination of MYJ scheme for the PBL and Monin-Obukhov (Janjic Eta) scheme (JAN) for the surface layer with the best scheme from CPS experiments (GD) can simulate the cyclone with the lowest error in terms of intensity prediction. The maximum wind speed in this scheme is $37.5 \mathrm{~m} / \mathrm{s}$ and the lowest CSLP is $974 \mathrm{hPa}$. This experiment also produces the maximum intensity of cyclone on 7 November 00 UTC, as seen in the CPS experiments. The RMS errors are listed in table 13. From the table, it is seen that the MYJ and JAN combination produce a low RMS error of $2.7 \mathrm{~m} / \mathrm{s}$ for the wind speed. Simulations for the MP experiments are presented in figures $8(\mathrm{~b})$ and 9 (b) and the corresponding RMS errors in the wind speed are listed in table 14. They show that the WRF Single Moment 3-class simple ice scheme (WSM3) is good for intensity prediction. The RMS values range between 1.9 and $4.3 \mathrm{~m} / \mathrm{s}$. The maximum wind speed is $36 \mathrm{~m} / \mathrm{s}$ and the lowest CSLP is $973 \mathrm{hPa}$ for the WSM3 scheme.

Figures 8(c) and 9(c) show the results of the land surface model simulations and indicate that the Pleim-Xu scheme (PLEIM) is good in terms of intensity prediction with the maximum wind speed and lowest CSLP value being $36 \mathrm{~m} / \mathrm{s}$ and $972 \mathrm{hPa}$, respectively. The RMS errors in the wind speed are given in table 15 and the lowest value is $1.8 \mathrm{~m} / \mathrm{s}$ for the case of PLEIM. Simulations with different

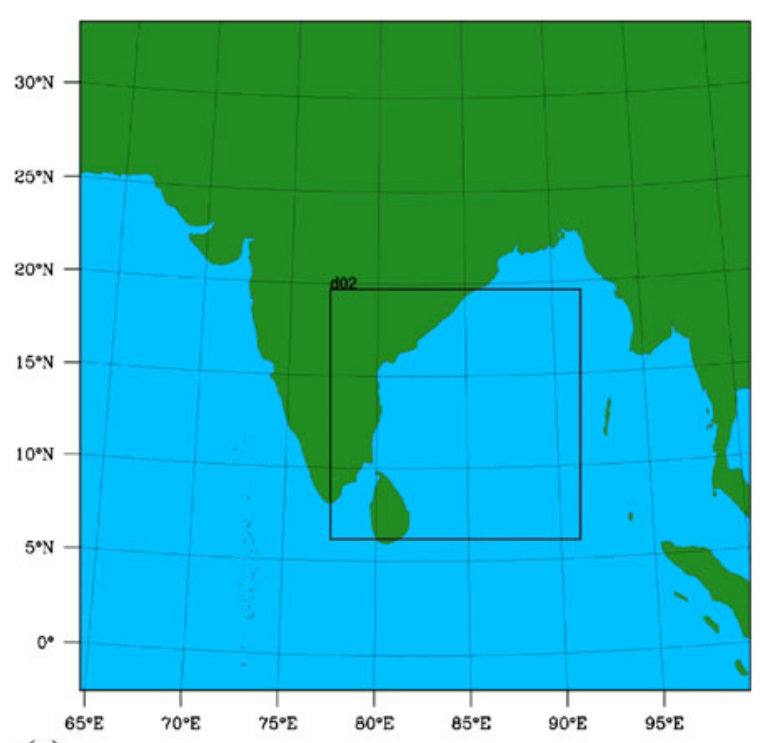

(a)

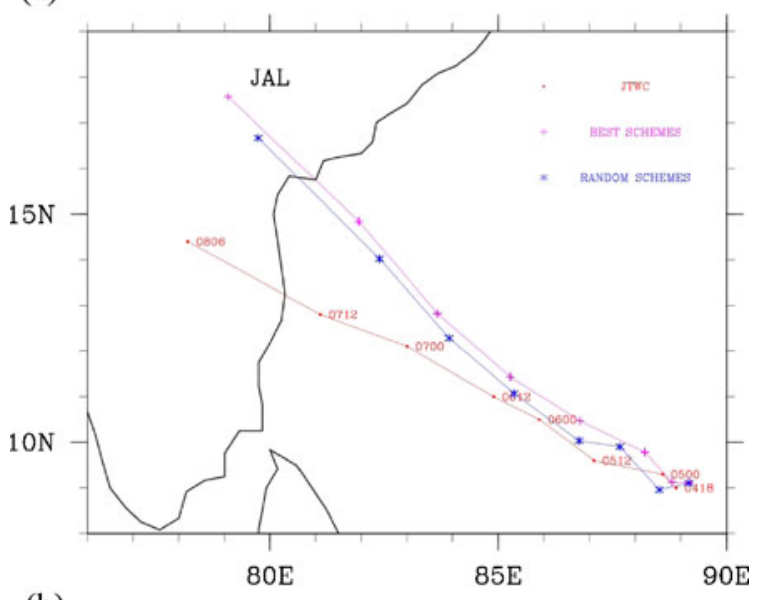

(b)

Figure 14. Nesting experiments (a) model domain (the resolution of the domain d01 is $30 \mathrm{~km}$ and domain d02 is 10 $\mathrm{km}$ ) and (b) simulated track propagation. 
SWR schemes resulted in the Dudhia scheme (DS) giving the best results in terms of intensity. Table 16 presents the RMS error and it is seen that the DS scheme is associated with an error of $1.8 \mathrm{~m} / \mathrm{s}$, the lowest among the three schemes. Figure $8(\mathrm{~d})$ shows that the maximum wind speed is $36 \mathrm{~m} / \mathrm{s}$ for the case of DS. Figure $9(\mathrm{~d})$ indicates that the CSLP values for this set of experiments and it is clear that DS scheme simulates the cyclone with the minimum CSLP being $972 \mathrm{hPa}$. Table 17 highlights the RMS errors for the two LWR scheme simulations and the values are $1.8 \mathrm{~m} / \mathrm{s}$ for the case of RRTM and $3.2 \mathrm{~m} / \mathrm{s}$ for the case of RRTMG. From figure $8(\mathrm{e})$ it is seen that the value of maximum wind speed is $36 \mathrm{~m} / \mathrm{s}$ for the RRTM and $36.5 \mathrm{~m} / \mathrm{s}$ the RRTMG. From the CSLP values shown in figure $9(\mathrm{e})$, it is seen that while the CSLP value is $972 \mathrm{hPa}$ for the RRTM it is 974.5 $\mathrm{hPa}$ for the case of RRTMG. The above values from the LWR schemes show that the RRTM scheme is good for intensity prediction. Finally, the best combination of physics schemes is listed in table 18.

\section{Structure of the cyclone}

The structure of the cyclone has been analyzed with best set of physics combination for wind prediction. Figure 10(a-d) shows the pressure contours and wind vectors of cyclone Jal for every
24 hours. From figure 10(a), it is seen that the system has a minimal CSLP of $1002 \mathrm{hPa}$ and maximum wind speed of $21.5 \mathrm{~m} / \mathrm{s}$ on 4 November 18 UTC. Figure 10(b) confirms that the system moved in a northwest direction and intensified into a cyclonic storm with the lowest CSLP of $988 \mathrm{hPa}$. The system has taken the energy from the warm sea waters and intensified into a very severe cyclonic storm on 7 November 18 UTC. Figure 10(c) shows that the system CLSP and wind speed are $975.46 \mathrm{hPa}$ and $36 \mathrm{~m} / \mathrm{s}$ on the same day. Figure 10(c) indicates that the cyclone loses energy after land fall and the maximum wind speed falls to $16.64 \mathrm{~m} / \mathrm{s}$. The wind vectors of $900,700,500$ and $300 \mathrm{hPa}$ during the mature stage of the cyclone corresponding to 7 November 00 UTC are presented in figure $11(\mathrm{a}-\mathrm{d})$. From the above figures it can be seen that the matured cyclone attained a maximum intensity corresponding to a CSLP of $972 \mathrm{hPa}$ and a maximum wind speed of $36 \mathrm{~m} / \mathrm{s}$. The figure shows that the cyclonic motions are strong up to $500 \mathrm{hPa}$ but at $300 \mathrm{hPa}$ the wind vector field shows no cyclonic motion and an anticyclonic motion near Myanmar. The vertical cross section of the wind along $82^{\circ} \mathrm{E}$ corresponding to 7 November 00 UTC is presented in figure 12(a) and clearly shows that the cyclonic strength wind extends throughout the troposphere. From figure 12(b), it is seen that the maximum vertical velocity reached is $6.4 \mathrm{~m} / \mathrm{s}$ on 5 November 00 UTC and after that vertical velocity decreases to $1.88 \mathrm{~m} / \mathrm{s}$ on 7 November 18 UTC.

Table 21. Comparison of track error ( $\mathrm{km}$ ) in the nesting experiments.

\begin{tabular}{|c|c|c|c|c|c|c|c|c|c|c|c|c|c|}
\hline Time (hr) & 6 & 12 & 18 & 24 & 30 & 36 & 42 & 48 & 54 & 60 & 66 & 72 & $\begin{array}{l}\text { RMS } \\
\text { error }\end{array}$ \\
\hline Best schemes (3 nesting) & 31 & 74 & 118 & 107 & 81 & 11 & 9 & 24 & 27 & 63 & 30 & 18 & 61 \\
\hline Best schemes (2 nesting) & 38 & 58 & 72 & 72 & 110 & 58 & 51 & 37 & 105 & 148 & 198 & 185 & 160 \\
\hline Random schemes (2 nesting) & 31 & 77 & 125 & 114 & 99 & 51 & 63 & 78 & 109 & 157 & 245 & 271 & 95 \\
\hline
\end{tabular}

Table 22. Randomly selected schemes.

\begin{tabular}{|c|c|c|}
\hline Sl. no. & Parameterization & Scheme \\
\hline 1 & Cumulus parameterization & Betts-Miller-Janjic scheme (BMJ) \\
\hline 2 & PBL & $\begin{array}{l}\text { Mellor-Yamada-Nakanishi-Niino } 2.5 \text { level } \\
\text { TKE (MYNN2.5) }\end{array}$ \\
\hline 3 & Microphysics & Kessler scheme (KS) \\
\hline 4 & Surface layer physics & $\begin{array}{l}\text { Monin-Obukhov (Janjic Eta) scheme } \\
\text { (JAN) }\end{array}$ \\
\hline 5 & Land surface model & $\begin{array}{l}\text { Rapid Update Cycle land-surface } \\
\text { model (RUC) }\end{array}$ \\
\hline 6 & Long wave radiation physics & Rapid Radiative Transfer Model (RRTM) \\
\hline 7 & Short wave radiation physics & $\begin{array}{l}\text { Rapid Radiative Transfer Model for } \\
\text { Global (RRTMG) }\end{array}$ \\
\hline
\end{tabular}




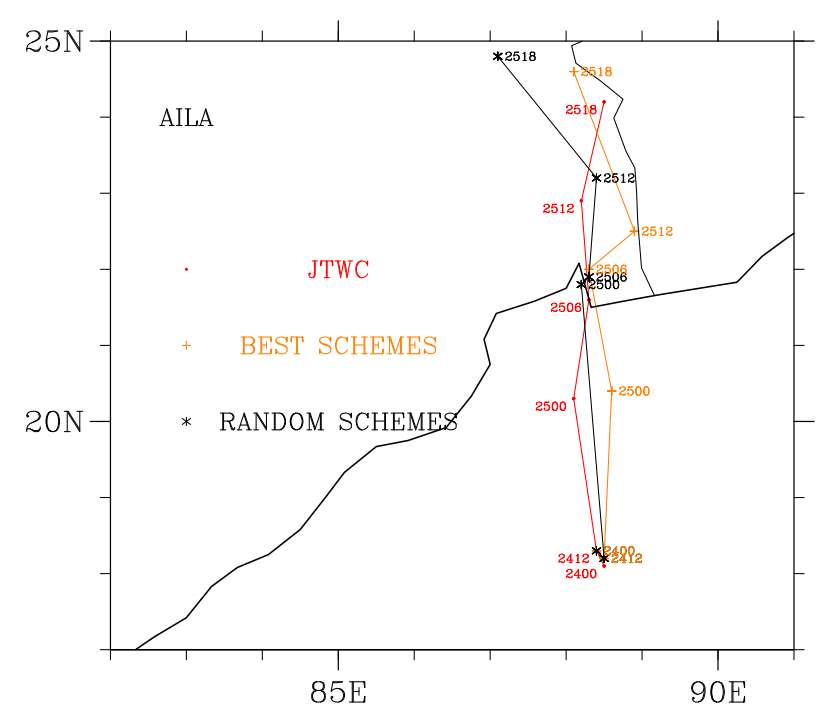

Figure 15. Simulated track propagation for cyclone Aila.

\section{Model sensitivity with orography and nesting}

An experiment was conducted to evaluate the effect of orography by including the Western Ghats in the third and innermost domain. The model domain used in this experiment is shown in figure 13(a) and results were obtained with and without the Western Ghats covered by the third innermost domain. The propagation of the track (figure 13b) shows that there is no significant difference. However, from table 19, it is seen that the land fall error is only $18 \mathrm{~km}$ when the domain is covered with Western Ghats as opposed to $46.04 \mathrm{~km}$ without it.
From figure 13(c) and table 20, it is seen that there is no significant change in wind prediction between the two options.

Experiments were also conducted to analyze the sensitivity of the predictions to the level of nesting. Two experiments have been conducted by using only one nesting domain (figure 14(a)) for cyclone Jal as follows: (i) simulations with best set of physics parameterization schemes and (ii) simulations with random physics options. Figure 14(b) shows the track propagation and it is seen that both simulations are close but deviate significantly from the JTWC track. Table 21 clearly establishes the superiority of the case of two nested domain.

\section{Simulation of tropical cyclone Aila}

Cyclone Aila was the second tropical cyclone in the year of 2009 in the north Indian Ocean. It formed on 23 May 2009 and had landfall over West Bengal on 25 May 09 UTC. The propagation and intensity of the cyclone Aila has been analyzed with best set of physics combinations determined from numerical experiments of cyclone Jal. Furthermore, simulations were also done with a randomly selected physics schemes from table 1 with the same initial and boundary conditions. The randomly selected options are listed in table 22 . The results of the two simulations were then compared. The simulations started on 24 May 00 UTC and the model has been run up to 25 May 18 UTC (42 hours). Figure 15 shows the simulated track propagation for the physics sets along with the JTWC observation cyclone track. Table 23

Table 23. Simulated track errors for cyclone Aila.

\begin{tabular}{|c|c|c|c|c|c|c|c|c|}
\hline Time (hr) & 0 & 6 & 12 & 24 & 30 & 36 & 42 & $\begin{array}{l}\text { RMS } \\
\text { error }\end{array}$ \\
\hline Best schemes & 28.1 & 107.9 & 10.9 & 53.5 & 44.8 & 87.6 & 60.8 & 68.3 \\
\hline Random schemes & 28.1 & 184.0 & 10.9 & 169.9 & 35.0 & 47.1 & 174.2 & 126.8 \\
\hline
\end{tabular}

Table 24. Cray CX1 technical specifications.

\begin{tabular}{|c|c|}
\hline Speed & 488.7 G flops based on high performance Linpack benchmark \\
\hline No. of Nodes & 6 (1 master node +5 compute nodes $)$ \\
\hline Total no. of CPU & 12 CPUs (2 CPUs per node) \\
\hline Total no. of core & 72 cores ( 2 cores per CPU; 12 cores per node) \\
\hline Processor & Intel Xeon six cores WX5660 2.80 GHz 12M 6.4 GT/sec \\
\hline \multirow[t]{2}{*}{ Memory } & $72 \times 4$ GB DDR3 $1333 \mathrm{MHz}$ \\
\hline & Total memory: 288 GB (48 GB per nodes) \\
\hline \multirow[t]{2}{*}{ Hard Drive } & $\begin{array}{l}250 \text { GB } 7.2 \mathrm{~K} \text { RPM SATA } 2.5 \text { " Internal fixed hard drive } \\
\text { in each nodes }\end{array}$ \\
\hline & 4TB External hard drive $(4 \times 1$ TB 7.2 RPM SATA 3 Gbps $)$ \\
\hline Operating system & Red hat Linux \\
\hline Compiler & Gfortran, Intel \\
\hline
\end{tabular}


highlights the RMS errors of the simulated cyclone track for 42 hours and it is seen that the best set of options from cyclone Jal sensitivity studies when applied to cyclone Aila produces a much better result compared to a random set of physics, thus justifying the elaborate sensitivity undertaken in this study. The technical specifications of the desktop mini supercomputer CRAY CX1 on which all the calculations were done are listed in table 24 .

\section{Conclusions}

Numerical experiments were conducted to determine the best combination of physics parameterization schemes for simulating both the track and intensity of cyclone Jal that originated in the north Indian Ocean in November 2010. Through this, several physics parameterizations in the WRFV3 model were exhaustively tested. The best combination of physics schemes for predicting the track was determined. Track errors were found to be very sensitive to Cumulus, PBL, microphysics and long wave radiation parameterizations. The land surface model and short wave radiation parameterization exert a less significant influence on the results. From this study, it is seen that the best scheme for track prediction invariably overpredicts the intensity. Hence, the best combination of physics schemes for intensity predictions was also obtained and is exactly the same way as was done for the track prediction. Results indicate that the cumulus parameterization has more impact on intensity prediction compared to other physics options. The PBL, microphysics, LWR and SWR also have significant impacts on intensity prediction while the land surface model exerted little influence. Upon detailed analyses from both set of experiments it is clear that the cumulus, PBL and microphysics play a major role in both the track and intensity predictions. Finally the best set of options and a random set of options were applied to cyclone Aila and it is seen that the best tracks are remarkably superior. Even so, from the above experiment it is clear that the best set of physics options proposed in this study is somewhat subjective and results are strongly influenced by domain size and the number of nested domains. Additional studies are required to investigate this further.

\section{References}

Deshpande M, Pattnaik S and Salvekar P 2010 Impact of physical parameterization schemes on numerical simulation of super cyclone Gonu; Natural Hazards 55(2) 211-231.

Krieger J 2009 Sensitivity of WRF model forecasts to different physical parameterizations in the Beaufort Sea region; In: Eighth Conference on Coastal Atmospheric and Oceanic Prediction and Processes in Phoenix, AZ, January 12-15.

Laprise R 1992 The Euler equation of motion with hydrostatic pressure as an independent variable; Mon. Weather Rev. 120(1) 197-207.

Loh W, Juneng L and Tangang F 2010 Sensitivity of Typhoon Vamei (2001) simulation to planetary boundary layer parameterization using PSU/NCAR MM5; Pure Appl. Geophys. 168(10) 1799-1811.

Mandal M, Mohanty U and Raman S 2004 A study on the impact of parameterization of physical processes on prediction of tropical cyclones over the Bay of Bengal with NCAR/PSU mesoscale model; Natural Hazards 31(2) 391-414.

Ooyama K 1990 A thermodynamic foundation for modeling the moist atmosphere; J. Atmos. Sci. 47(21) 2580-2593.

Pattnaik S and Krishnamurti T 2007 Impact of cloud microphysical processes on hurricane intensity. Part 2: Sensitivity experiments; Meteorol. Atmos. Phys. 97(1) $127-147$.

Prater B and Evans J 2002 Sensitivity of modeled tropical cyclone track and structure of Hurricane Irene (1999) to the convective parameterization scheme; Meteorol. Atmos. Phys. 80(1) 103-115.

Rao D and Prasad D 2007 Sensitivity of tropical cyclone intensification to boundary layer and convective processes; Natural Hazards 41(3) 429-445.

Skamarock W 2008 A description of the Advanced Research WRF version 3; NCAR Tech. Note NCAR/TN-475+STR.

Skamarock W and Klemp J 2008 A time-split nonhydrostatic atmospheric model for weather research and forecasting applications; J. Comput. Phys. 227(7) 3465-3485.

Srinivas C, Venkatesan R, Bhaskar Rao D and Hari Prasad D 2007 Numerical simulation of Andhra severe cyclone (2003): Model sensitivity to the boundary layer and convection parameterization; Pure Appl. Geophys. 164(8-9) 1465-1487.

Yang M and Ching L 2005 A modeling study of Typhoon Toraji (2001): Physical parameterization sensitivity and topographic effect; Terr. Atmos. Ocean. Sci. 16 177-213. 